\title{
A cross-cultural study of the perceived benefits of a retailer loyalty scheme in Asia
}

\author{
Peter Steyn ${ }^{\mathrm{a}}$, Leyland Pitt ${ }^{\mathrm{b}}$, Arien Strasheim ${ }^{\mathrm{c}}$, Christo Boshoff ${ }^{\mathrm{d}}$, Russell Abratt ${ }^{\mathrm{e}, *}$ \\ ${ }^{a}$ Division of Industrial Marketing, eCommerce and Logistics, Lulea University of Technology, Lulea, Sweden \\ b Segal Graduate School of Business, Simon Fraser University, Vancouver, BC, Canada \\ ${ }^{c}$ Department of Marketing and Communication Management, University of Pretoria, Pretoria, South Africa \\ ${ }^{\mathrm{d}}$ Department of Business Management, University of Stellenbosch, Stellenbosch, South Africa \\ e Huizenga School of Business and Entrepreneurship, Nova Southeastern University, and Wits Business School, University of the Witwatersrand, \\ 3301 College Avenue, Fort Lauderdale, Florida, USA
}

\section{A R T I C L E I N F O}

Keywords:

Loyalty schemes

Asia

Loyalty cards

Reward programmes

\begin{abstract}
A B S T R A C T
The aim of this paper is to explore loyalty, loyalty schemes, and loyalty cards, as well as the internationalisation of loyalty schemes. We focus on loyalty schemes in Asia to define the primary objective of our study: to assess the impact of perceived benefits on the feelings of participants of a specific retailer's loyalty scheme, as well as customer loyalty towards the retailer. A literature review of loyalty schemes and loyalty cards is undertaken as well as the internationalisation of these cards. A survey was conducted in five Asian countries in which Toys'R'Us operates, namely Singapore, Malaysia, Hong Kong, Taiwan, and Thailand. Data was collected among members of the Toys'R'Us Star Card loyalty programme. Structural equation modelling was used to build a model that can be used to explain the simultaneous structural relations between perceived benefits, emotional feelings, and loyalty behaviours. Invariance testing was applied in order to test whether the model holds across the five countries. Our findings suggest that perceived benefits have a weak direct effect on loyalty behaviours. However, perceived benefits have a much stronger effect on feelings, which in turn have a strong effect on loyalty behaviours. We also found subtle differences between the countries in the study, which could either be attributed to cultural differences, to marketing practices, or to both, which can only be ascertained through further research.
\end{abstract}

(c) 2010 Elsevier Ltd. All rights reserved.

\section{Introduction}

The importance of consumer loyalty in business is a recurring theme in the contemporary marketing literature (Noordhoff et al., 2004; Turner and Wilson, 2006). Some even believe that consumer loyalty is emerging as the marketplace currency of the twenty-first century (Singh and Sirdeshmukh, 2000). In very competitive industries and saturated markets, and often as a consequence of developments such as new technologies, the strategic importance of customer loyalty has remained topical. Although marketers have used a variety of tactics and strategies over the years to encourage and enhance customer loyalty, the most popular option has been the implementation of so-called loyalty schemes. During the year 2000, it was estimated that the 16 largest retailers in Europe spent around $\$ 1$ billion on loyalty initiatives (Reinartz and Kumar, 2002), and that there were over

\footnotetext{
* Corresponding author. Tel.: +19542625123.

E-mail address: Abratt@nova.edu (R. Abratt).
}

40 million loyalty cards in circulation in Britain alone (Byrom, 2001).

However, there are still no clear indications as to whether these initiatives are successful with some research supporting the value of loyalty cards to retailers (Lewis, 2004; Taylor and Neslin, 2005; Meyer-Waarden, 2007; Lal and Bell, 2003) while others are not as supportive of its value (Sharp and Sharp, 1997; Passingham, 1998; Liebermann, 1999; Mauri, 2003; Mägi, 2003; Ergin et al., 2007).

Many airlines report that the contingent liability created by frequent flyer points and miles runs into millions of dollars. It is estimated that 8000 billion air miles are currently unused by people who collect, but cannot use them. The world's airline fleet is too small to redeem more than a fraction of these loyalty rewards (Collins, 2002). Rather disconcertingly, many consumers claim that loyalty cards do not influence their shopping behaviour, while many report that they do not have the right cards with them at the time of shopping or simply forget to use them (Loyalty card fatigue has set in among consumers, 2008). Consumers often experience frustration with loyalty reward schemes due to qualification barriers, time and place barriers in 
reward redemption, and unappealing rewards (Berman, 2006). Stauss et al. (2005) even identified seven different categories of frustration that could be triggered by loyalty reward programmes and then subsequently result in frustration behaviour of consumers.

There is the possibility that what loyalty scheme works in one country may not work in another, and that there may be variation across countries and across different cultures. In addition, this type of measurement has been confounded in general by the failure of researchers to assess the invariance of the scales used in cross-national or cross-cultural research (Steenkamp and Baumgartner, 1998).

In this paper we first explore loyalty, loyalty schemes, and loyalty cards, as well as the internationalisation of loyalty schemes. We then focus on loyalty schemes in Asia to define the primary objective of our study: to assess the impact of perceived benefits on the feelings of participants of a specific retailer's loyalty scheme, as well as customer loyalty towards the retailer. The theoretical model underlying our problem statement and research objectives is then discussed, followed by an outline of our methodology, data analysis, and findings. We then discuss the managerial implications of our research and conclude by acknowledging the limitations of the study, and identify avenues for future research.

\section{Loyalty, loyalty schemes, and loyalty cards}

Customer loyalty has been defined in a variety of ways, from a probability of repurchase to a proportion of purchase perspective (Sivadas and Baker-Prewitt, 2000). At a general level, customer loyalty can be described as a positive propensity toward a store or brand (East et al., 2000). Some believe that there are two types of consumers, namely those who are intrinsically loyal and stay with the same store or brand, and potential switchers who, on every purchase occasion would objectively consider all available products or brands and then make a choice independent of previous buying (Colombo and Morrison, 1989). In reviewing different measures of propensity towards brands and stores, Dick and Basu (1994) and Mellens et al. (1996) concluded that loyalty is both a cognitive construct (attitude) and a shopping behaviour.

Based on the dimensions of attitude and shopping behaviour, Dick and Basu (1994) classify customers into four groups-'True Loyals' (high attitudinal and behavioural loyalty), 'Latent Loyals' (high attitudinal but low behavioural loyalty), 'Spurious Loyals' (low attitudinal but high behavioural loyalty) and 'Non-Loyals' (both low attitudinal and behavioural loyalty).

Subsequent research (Kim et al., 1998) suggested the inclusion of an 'affective component' as an element of brand loyalty, thus rendering brand loyalty as a construct containing affective, cognitive, and behavioural aspects. However, as the affective and cognitive aspects of brand loyalty are captured by 'attitude', it can be concluded that loyalty consists of the two dimensions as defined by Dick and Basu (1994). More recently, Russell-Bennett et al. (2008) reported a significant relationship between attitudinal and behavioural loyalty and they suggest that high levels of attitudinal loyalty are antecedent to high levels of behavioural loyalty. This study offers empirical support for a broadened perspective on earlier loyalty research.

One common tactic to encourage customer loyalty at both the cognitive and the behavioural level is the use of so-called loyalty schemes and loyalty cards of which retailer Tesco in Britain is arguably the prime example (Turner and Wilson, 2006). The adoption rate of loyalty cards has been staggering. By 2003, 85\% of UK households were found to hold at least one loyalty card (Hobbs and Rowley, 2008). Research conducted by the online community
Pigsback.com and loyalty management company Reward, suggests that $98 \%$ of those they surveyed had a loyalty card and almost two thirds have three cards or more (Loyalty card fatigue has set in among consumers, 2008). It is estimated that one in two Brits own a Tesco Clubcard (Retailers play loyalty card, 2008, p. 26). This rapid rate of adoption has its downside, however, with some commentators referring to "loyalty-card fatigue", "loyalty overload" and a "backlash" against loyalty cards. The primary reason for this negative sentiment is that many consumers believe the incentives on offer are not worth the effort. In other words, the customer considers that their inputs relative to the available benefits do not justify their participation.

\section{Customer benefits}

Perceptions are often described as how "we see the world around us". In a marketing and consumer behaviour context, perceptions refer to how consumers assimilate marketing stimuli from a variety of different sources and integrate it all into some "whole" that influences consumer decision-making. Marketers spend much of their time and effort in establishing or changing consumer perceptions. This they often do by means of promises (Bitner, 1995). For instance, marketers make promises both explicitly (i.e., by means of advertising) or implicitly (i.e., customers observing the good service provided by frontline staff).

Marketers of customer relationship or loyalty programmes explicitly promise benefits to potential participants. These promised benefits may be lower prices, free products, or even cashback offers. Recent research (Anisimova, 2007) found that functional consumer benefits are the most critical and consistent predictors of both attitudinal and behavioural loyalty. A successful loyalty programme depends heavily on the extent to which both parties benefit from the programme (Berry, 1995, p. 243; Bitner, 1995 , p. 246). The benefits for retailers, for instance, will be increased sales and access to consumer data (Mauri, 2003). If the company does not see any benefits in a loyalty programme, they will either not initiate one or terminate an existing one. The same applies to customers. When they do not see sufficient benefits or do not truly believe there is any value in participation, they simply would not participate (Target Corporation's Smart Visa Rewards Campaign is a case in point), or withdraw from the scheme, or abuse it. Companies such as HSBC, Asda, and Safeway have recently terminated their loyalty schemes (Capizzi and Ferguson, 2005). Despite the occasional failure, loyalty schemes have proliferated and several Western firms have extended their loyalty schemes to other parts of the world.

\section{The internationalisation of loyalty schemes}

Although loyalty schemes and loyalty cards have their origin in the early 1990s in the UK, today they are an international phenomenon. In Turkey, the Garanti Bank Bonus MasterCard programme already has 2 million members. This coalition programme now boasts 750 stores with over 18,000 outlets where cardholders can redeem Bonus Points. Since the programme launched in April 2000, Garanti claims that members have redeemed US\$22 million in cash value awards and US\$13 million in goods and services. Tesco is rolling out their Clubcard in nine countries including China, South Korea, and Thailand. UKbased smart card supplier ID Data recently won a deal to provide 1.4 million cards for Premium Club, the first coalition loyalty programme in Poland-a number nearly equal to the population of Warsaw. Japanese bank JCB International and Singapore shopping mall Bugis Junction announced the joint launch of the Bugis Junction Mizu Card, the first chip-based credit card to offer a 
loyalty programme from all the retail tenants in an entire Asian shopping centre (Capizzi and Ferguson, 2005).

The impact of these loyalty schemes on actual loyalty is, however, not consistent across countries. Bellizzi and Bristol (2004) found that loyalty cards do not impact on customer's supermarket loyalty in the USA as did Ergin et al. (2007), in respect of store loyalty in Turkey. These findings are again contradicted by Meyer-Waarden (2008) in a study in France, by Turner and Wilson (2006) in a study of Tesco Clubcard owners in the UK, and by Gómez et al. (2006) in a study of both behavioural and affective loyalty in Spain, which suggest that cultural influences may impact on the successful implementation of loyalty schemes.

\section{The cultural influence on loyalty schemes: the case of Asian countries}

Given the saturation of loyalty cards in the Western world, many American and European retailers have targeted Asian markets in particular in recent years (Ganesan, 2001), where markets are not only growing faster, but "loyalty-card fatigue" has not yet set in (Loyalty Cards and Customer Behaviour, 2005, p. 18). However, there is evidence that Asians may have behaviours, loyalty attitudes, and other consumer attitudes that differ from their Western counterparts.

Noordhoff et al. (2004), in a comparative study of Singaporean and Dutch consumers, have argued on theoretical grounds, that Westerners would be different from Asians in respect of both attitudinal store loyalty and behavioural loyalty as well as in terms of the role of loyalty-card possession in prediction of both types of loyalty. They found that while Dutch and the Singaporean consumers do not differ in terms of behavioural store loyalty, the attitudinal store loyalty of the Singaporeans is higher than that of the Dutch. In similar vein, they found that while loyalty-card possession among the Dutch exerts a positive influence on attitudinal store loyalty, the same could not be said for the Singaporeans.

As retailers expand their operations and loyalty-card programmes across countries and regions, they should be sensitive to the effect of culture. Ferraro (2002) defines culture as "everything that people have, think and do as members of their society" while Hofstede (1994) has defined culture as "the collective programming of the mind which distinguishes the members of one group from another".

Several cultural norms distinguish some, or most, of the Asian countries from other regions. Asians' cultural differences that would, to some degree or another, have an impact on marketing loyalty strategies which are: collectivism rather than individualism; avoidance of inter-personal disharmony; emphasis on the social role of groups; more submissive behaviour in groups; avoidance of disagreements; a shift to the majority position; individual goals subordinated to goals of group; respect for authority; and avoidance of uncertainty (Hofstede, 1994; Banks, 1997; Hofstede and Bond, 1998). While cultural values and norms generally provide some explanations about the similarities in the behaviour of individuals (Ackerman and Tellis, 2001), culture and nation are not necessarily synonymous, as most countries in Asia do not have a homogeneous culture. Singapore, as example, has some characteristics of a Confucian culture from their Chinese population, but also elements of non-Confucian society from their Malay and Indian population.

The impact of culture on loyalty programmes can be significant as consumers rely on cultural norms in their decision making (Briley and Aaker, 2006). Straughan and Albers-Miller (2001) reported that cultural individualism is negatively correlated with loyalty to domestic retailers, while uncertainty avoidance is positively correlated to loyalty. Kivetz and Simonson (2003) point out the importance of individual differences and cultural norms (e.g., demographics, need for achievement, sensitivity to social comparisons, need for cognition) in the selection of types of reward benefits.

\section{Problem statement}

Investment in loyalty programmes is substantial, global, and is rapidly expanding. Questions remain whether these investments provide positive returns to marketers. It is difficult to directly quantify the income generated by loyalty programmes since transactions cannot be isolated, and there is no "control group". An approach to provide some indication of the value of loyalty programmes is to investigate it from a customer and loyalty perspective. Consumers can be solicited on what they perceive to be the most important benefits, as well as about their emotional feelings about the store and using the loyalty card, thereby tapping into aspects of emotional branding. Finally, probing customers about their loyalty behaviour might enable marketers to establish how perceived benefits, feelings and loyalty interplay from a consumer behaviour perspective.

We address the question of whether consumer perceptions of the perceived benefits of a loyalty scheme influence both their feelings towards the scheme, and loyalty intentions, in several Asian countries.

\section{Objectives}

The primary objective of this study was to assess the impact of the perceived benefits of a loyalty-card scheme on the feelings of participants of the scheme in an established retailer, and on their loyalty towards this retailer.

There have been a growing chorus of calls for the validation of measuring instruments and research results across different countries (cf., Bagozzi, 1994). The question needs to be answered whether the instrument employed to measure the constructs under study in cross-national or cross-cultural research are invariant. Steenkamp and Baumgartner (1998, p. 78) argue:

"If evidence supporting a measure's invariance is lacking, conclusions based on that scale are at best ambiguous and at worst erroneous. For example, cross-national differences in scale means might be due to true differences between countries on the underlying construct or due to systematic biases in the way people from different countries respond to certain items".

Failure to assess the measurement invariance of an instrument used in cross-national or cross-cultural research thus seriously compromises the validity of the reported results. Against this background a secondary objective of this study was to assess the invariance of the scale used to measure the perceived benefits and the feelings of the loyalty scheme of a participating retailer (the multinational toy retailer, Toys'R'Us) in five selected Asian countries.

\section{The theoretical model}

To address both the problem statement and the resultant objectives we constructed a theoretical model based on the wellknown tri-component attitude model of Rosenberg and Hovland (1960). According to this model, attitudes consist of three components, namely cognition (knowledge and perceptions, i.e. beliefs), affective (feelings and emotions), and conation (the behavioural 
element). In our study we hypothesise that consumers' perceived benefits (knowledge, perception) of a loyalty card will influence their feelings toward it, and that will in turn influence their behaviour. In this case we model loyalty as "actual reported loyalty behaviours".

The resultant hypotheses are:

$\mathbf{H}_{1}$. The perceived benefits associated with a loyalty scheme will positively influence card holders' emotional feelings towards the scheme

$\mathbf{H}_{2}$. The perceived benefits associated with a loyalty scheme will positively influence card holders' loyalty behaviours

H3. The emotional feelings associated with a loyalty scheme will positively influence card holders' loyalty behaviours

\section{Method}

\subsection{Sampling}

The survey was conducted in five Asian countries in which Toys'R'Us operates, namely Singapore, Malaysia, Hong Kong, Taiwan, and Thailand. The questionnaire was translated to the official languages of each country using accepted practice in questionnaire translation (forward and backward translation) and pre-tested in each language. Respondents were also offered an option to use the English questionnaire. In each of the five countries, the survey was emailed to a random selection of current members of the Toys'R'Us Star Card membership lists. Qualifying members should have made a purchase at the store in the past 12 months (or contacted the Customer Hotline) and should have been members for at least 12 months. A small reward, in the form of Star Card Points, was used as an incentive to those who completed the survey.

\subsection{Measurement}

The survey questions can be grouped into three, namely questions referring to benefits, questions referring to feelings, and lastly, questions about loyalty behaviours. The statements aimed at measuring perceived benefits were measured using a 5-point Likert scale as shown in Table 1.

The emotional feeling about the loyalty card was tapped using eight statements as shown in Table 2. This was measured on a 5-point Likert scale.

Finally, loyalty behaviours were measured using three variables as shown in Table 3, using a 4-point scale with $1=$ Never, $2=$ Seldom, $3=$ Sometimes, and $4=$ Always.

Table 1

Items indicating perceived benefits.

\begin{tabular}{ll}
\hline B1 & Points with every purchase \\
B2 & Your points give you reward coupons every 4 months \\
B3 & Star offers allow exclusive savings for members \\
B4 & Priority session for members at warehouse sale \\
B5 & Fun bonus: buy $\$ 350$ and get $\$ 70$ toy coupon \\
B6 & Special offers from Star Card partners \\
B7 & Summer/Christmas catalogue mailed directly \\
B8 & Email newsletters with latest offers, deals, news \\
B9 & 45 days refund period for Star members \\
B10 & Star Card Customer Hotline \\
\hline
\end{tabular}

Scale: 5 -point Likert scale with $5=$ Excellent value and $1=$ Poor value.
Table 2

Items indicating emotional feelings about the loyalty card. F1Star Card makes shopping at Toys'R'Us greater va

F2 I get more savings while shopping at Toys'R'Us

F3 I get better service as a Star Card member

F4 Star Card makes shopping at Toys'R'Us easier

F5 Star Card benefits provide an additional reason for shopping at Toys'R'Us

F6 I feel good to be a Star Card member

F7 As a Star member I feel special in the store

F8 Star Card is overall the best shopping loyalty programme

Scale: 5 -point Likert scale with $5=$ Strongly agree and $1=$ Strongly disagree

Table 3

Items indicating loyalty behaviours.

USEFREQ Use frequency: “When shopping at Toys'R'Us, how often do you use your Star Card?"

CARRFREQ Carry frequency: "Do you carry your Star Card with you, such as in your pocket, wallet, purse, or handbag?"

RECOMM Recommendation propensity: "How often do you recommend others such as your friends and relatives to become Star Card members?"

Scale: 4 -point scale: $1=$ Never, $2=$ Seldom, $3=$ Sometimes, and $4=$ Always.

\section{Data analysis and results}

The number of completed surveys analysed (response rate) by country is as follows: Singapore $=3183(27.2 \%)$, Malaysia $=3042$ (23.4\%), Hong Kong=4576 (35.3\%), Taiwan=2700 (21.2\%), and Thailand $=2489$ (26.2\%), for a total of 15,990 surveys analysed across the five countries. The effective overall response rate was $26.6 \%$.

The analyses followed four stages. First, exploratory principal component factor analysis was used to explore the dimensionality of the three concepts. Second, stepwise regression was used in order to select items that were best at indicating the selected predictors of loyalty, and third, structural equation modelling was used to build a model explaining the simultaneous structural relations between benefits, feelings, and loyalty. Finally, invariance testing was applied in order to test whether the model holds across the five countries.

\subsection{Exploratory factor analysis results}

In order to assess the dimensionality of the data as a single sample $(n=15,990)$, principal component exploratory factor analysis was performed on the ten benefit items. The results revealed a single benefit factor. The procedure was repeated, for each of the five countries in the sample individually, using the eigenvalue greater than 1 criterion for the number of factors to be extracted. For Hong Kong, Taiwan, and Thailand samples, only a single benefit factor was extracted. For the Singaporean and Malaysian sample, however, two benefit factors were extracted from the ten benefit items. The two factors extracted for Singapore and Malaysia, referred to financial benefits as measured by items B1-B3 (Cronbach's $\alpha=0.705$ ) and information benefits as reflected in items B4-B10 (Cronbach's $\alpha=0.857$ ). When the corrected item-total correlations were inspected, none of the correlations suggested the removal of any of the items.

When the feeling items (F1-F8) were subjected to exploratory principal components factor analysis, a single factor emerged for both the entire sample of 15,990 responses, as well as the country-by-country analyses. Therefore, the eight feeling items clearly loaded onto a single feeling factor. The item communalities varied between 0.587 and 0.734 , and the Cronbach's $\alpha$ was equal to 0.929 for all eight items across all five countries. 
Based on these findings, the standard procedure for selecting the better items and identifying items to be removed from a construct becomes ineffective. This problem is typical of very large data sets and a large pool of items, so that the construct under investigation becomes "unavoidably reliable", and the usual method of removing items based on low item-total correlations cannot be used.

In order to have a more parsimonious model of measuring perceived benefits and feelings, and to ascertain how they link with loyalty behaviours, a stepwise regression procedure was followed.

\subsection{Stepwise regression analyses}

It would be useful for retailers if a smaller number of items indicating benefits and feelings could be identified that could validly and reliably predict the loyalty behaviour of shoppers. Respondent fatigue is often cited as a reason for poor response rates and to select survey items to include in an abbreviated form, the entire sample as well as the individual country samples was used to perform regression analyses.

Stepwise regression sequentially selects the variable that provides the "best explanation" of the dependent variable. The stepwise procedure first selects the variable that has the highest correlation with the dependent variable. During the next stage, all the variables in the equation are adjusted for the variable that has been entered into the model first. If predictor variables are therefore highly correlated, they may not be included in the subsequent phases of the stepwise procedure, since their effect may have been removed through the adjustment. The procedure is repeated until additional variables added into the model are not making a significant improvement to the model. Once the effect of the selected variable has been removed, the residuals are regressed on the remaining predictors. The process is repeated until no more predictors can be added to the model.

In the stepwise regression analyses, three variables were used as dependent variables, namely "Usefreq", the frequency with which the card was used when shopping at the store, "Carrfreq", the frequency with which the card was always carried with the shopper, and "Recomm", the propensity to recommend the card to friends and family. All these variables were measured on a 4 -point scale, ranging from $1=$ Never to $4=$ Always (Table 3 ). The stepwise regression analyses were run for each of three dependent variables, namely "Usefreq", "Carrfreq", and "Recomm", using the ten items indicating benefits as predictor variables, across the five countries individually and the entire group pooled. In total the results of 18 stepwise regression analyses were evaluated, using a criterion of order of selection and the frequency of selection across the dependent variables. The benefit items that were "best" to predict loyalty behaviours across the three dependent variables were items B1, B2, B3, B7, and B8.

In the same manner, the procedure was repeated for the feeling items, resulting in another 18 stepwise regression analyses, and the items that were highest on the selection rank order and most frequently selected in the stepwise procedure were items F4, F5, F7, and F8. It was therefore decided to retain these items only for the SEM-model.

From the analyses presented so far, subsets of items emerged as possible predictors of loyalty behaviour. The Cronbach's coefficient alpha for the subsets of items are presented in Table 4.

\subsection{Structural equation model (SEM) analysis for all countries}

Using a SEM-model instead of separate independent regression models to investigate differences and similarities across countries has several advantages. The measurement part of the model with the respective latent variables can be modelled with several
Table 4

Cronbach's $\alpha$ for item subsets by country.

\begin{tabular}{|c|c|c|c|c|c|c|}
\hline \multirow[b]{2}{*}{ Country } & \multicolumn{6}{|c|}{ Cronbach's coefficient alpha $(\alpha)$} \\
\hline & Malaysia & Singapore & $\begin{array}{l}\text { Hong } \\
\text { Kong }\end{array}$ & Taiwan & Thailand & All \\
\hline $\begin{array}{l}\text { Items } \\
\text { FINBEN }^{\mathrm{a}}\end{array}$ & $n=3042$ & $n=3183$ & $n=4576$ & $n=2700$ & $n=2489$ & $n=15990$ \\
\hline $\begin{array}{l}\text { B1, B2, B3 } \\
\text { INFBEN }\end{array}$ & 0.698 & 0.707 & 0.716 & 0.755 & 0.656 & 0.708 \\
\hline $\begin{array}{l}\text { B7, B8 } \\
\text { Feelings }\end{array}$ & 0.731 & 0.670 & 0.630 & 0.663 & 0.601 & 0.662 \\
\hline $\begin{array}{l}\text { F4, F5, F7, } \\
\text { F8 }\end{array}$ & 0.894 & 0.875 & 0.867 & 0.887 & 0.854 & 0.884 \\
\hline
\end{tabular}

a Construct measured.

dependent variables simultaneously, and the dependent variable can be modelled as a latent variable. A further advantage is that several alternative models can be compared directly. Parameter restrictions can be imposed and the effects can be evaluated using an SEM approach. Multiple groups can be accommodated using a hierarchical procedure to evaluate the fit of the model, and correlated errors can be accommodated in the model which is not possible with ordinary regression models.

Therefore, a SEM approach in testing the relationships among the benefit variables and the feeling variables, and their relationships to the three dependent variables that relate to loyalty behaviour was the approach followed in this study. In the initial analyses, all the countries were combined in a single sample in order to develop a holistic model that can be used to predict loyalty behaviour, the construct of primary concern.

Based on the findings in the initial exploratory factor analyses, a model was developed and investigated for its plausibility over all five countries.

The initial conceptual model is shown in Fig. 1, and has items B1, B2, and B3 modelled as indicators of the latent variable "finben", the financial benefits associated with the loyalty programme. Items B7 and B8 are modelled as indicators of "infben", the information benefits associated with the loyalty programme. Financial benefits and information benefits are correlated, and further modelled to have an effect on both feelings and loyalty, with the latent variable feelings measured by items F4, F5, F7, and F8, and loyalty measured by the behavioural variables Usefreq, Carrfreq, and Recomm. The latent variable feelings, is also modelled to have an effect on loyalty. This model enables us to answer questions like the following:

- Do perceived financial benefits have a stronger effect on feelings and loyalty than information benefits?

- Which indicator of loyalty is the strongest, Usefreq, Carrfreq, or Recomm?

- Are there any differences between countries with respect to the questions raised above?

The model was subjected to the combined samples as a single data set, and was found to fit reasonably well. However, inspection of the modification indices suggested that the measurement errors between B1 and B2 are correlated, and since both items refer to benefit points, the correlated error makes sense and this correlation was included in the model. Similarly, the measurement errors of B2 and B8 were correlated, the reason may be that the coupons (referred to in item B2) are usually emailed (referred to in item B8) to Star Card members. Among the items indicating feelings, F4, F7, and F8 have significant correlated errors, and they make sense if the contents of the items are compared. Finally, there is a significant correlated error between 


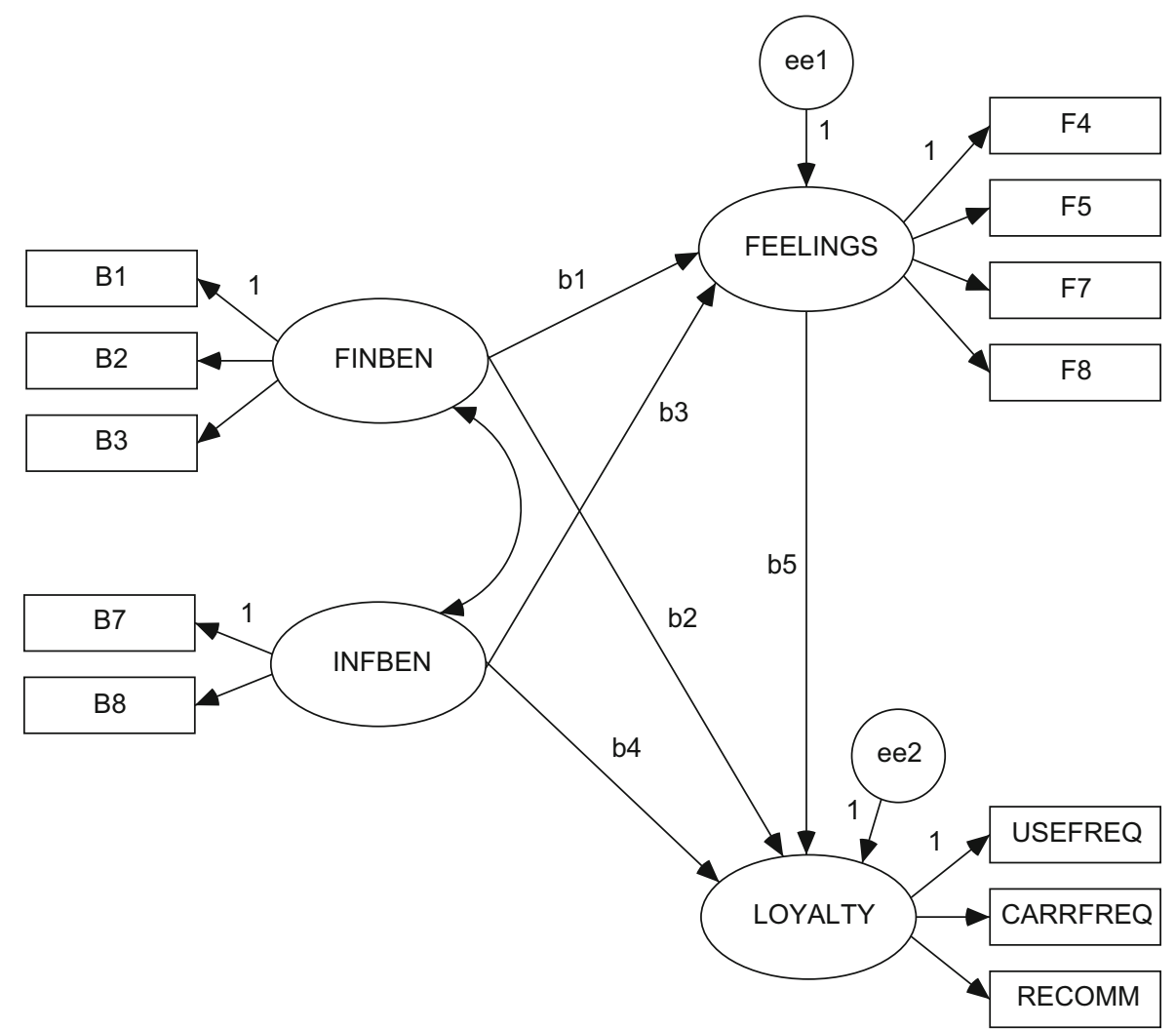

Fig. 1. Conceptual model to predict loyalty behaviours from perceived benefits and feelings evoked by the loyalty programme.

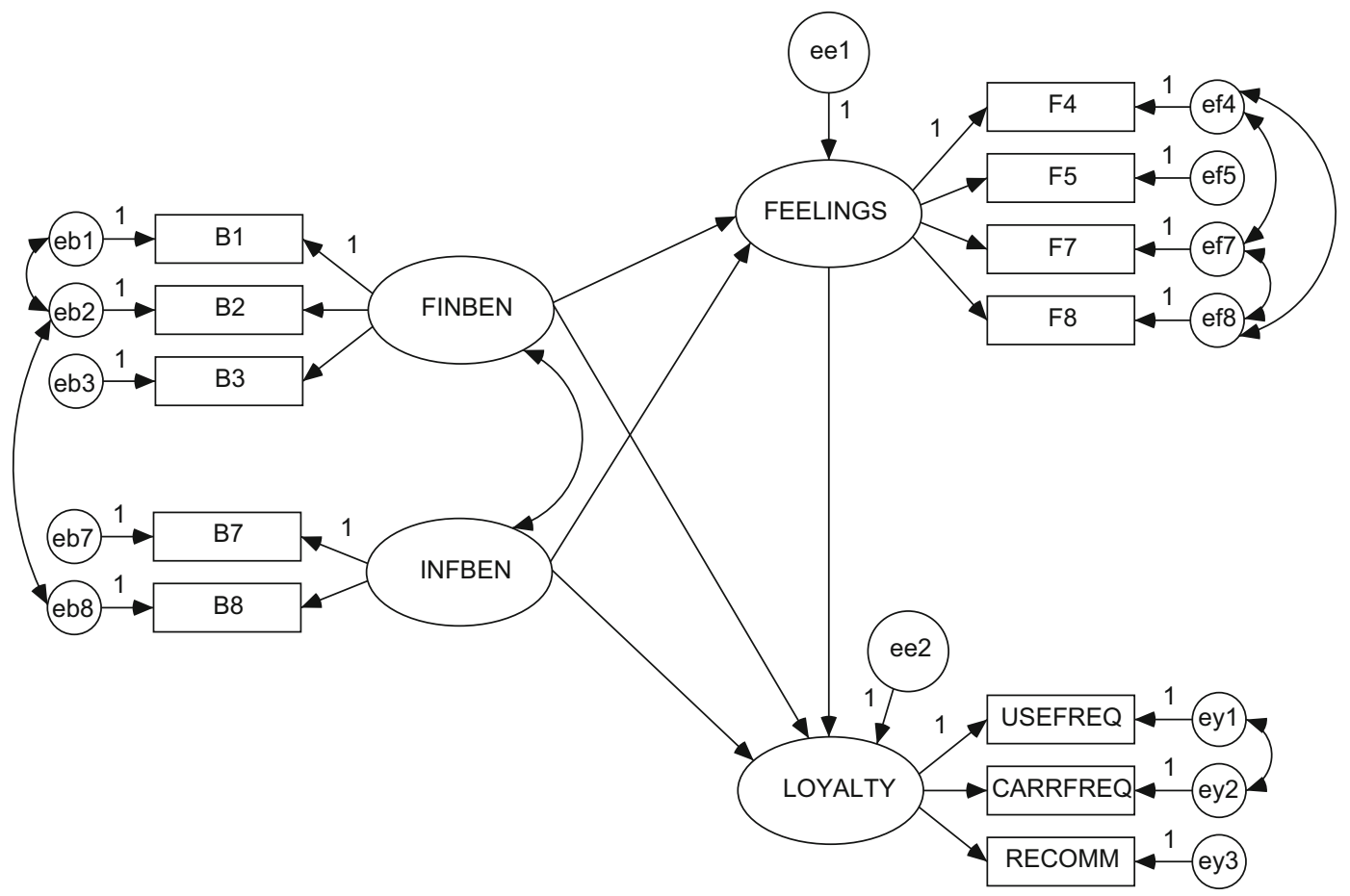

Fig. 2. Final model with error covariances.

the items Usefreq and Carrfreq for obvious reasons-if the star card is carried frequently, it will also be used frequently. These correlated errors were therefore included in the model and are not regarded as major re-specifications of the model, since the additional parameters are reflecting measurement artefacts rather than structural aspects of the model. The model with correlated errors is shown in Fig. 2.

The more pertinent question that arises after the finer adjustments in the model, is how does the model fit across individual countries, and if there are differences between countries, how 
could these be explained? Are loyalty behaviours affected differently based on benefits perceived from using the Star Card, and how does the perceived benefits influence the emotional feelings of card users? How do feelings affect loyalty behaviours? Are there any peculiar differences across the different cultural groups? Therefore, for the last phase of the data analysis we investigated the equivalence of our model across five countries.

\subsection{Model equivalence across five countries}

When the plausibility of the model across all five countries was investigated using a hierarchical testing procedure (Steenkamp and Baumgartner, 1998) the procedure quickly breaks down. However, if the model is applied to the Malaysian and Singaporean samples alone, a very plausible model emerges, and very interesting similarities and minor differences across these two countries could be found. When the model was tested for Hong Kong, Taiwan, and Thailand samples, very few similarities could be found, and their results are required to be discussed separately.

In the SEM approach, the null hypothesis is stated in a way that is not the norm in most statistical analyses. The null hypothesis is that the model fits the data exactly, and in most cases, the researcher is interested in not rejecting the null hypothesis. Since this hypothesis is very restricting, it is not unusual to reject the null hypothesis. A further problem is that, in contrast to the case in most other statistical methods, rejection of the null hypothesis is more likely as the sample size increases. This fundamental logic of SEM does pose specific challenges in the evaluation of model fit. It is therefore important to follow a variety of approaches when model fit is evaluated.

The $\chi^{2}$ value is used as an inferential goodness-of-fit measure to test the null hypothesis that the model fits the observed covariance matrix perfectly. According to Raykov and Marcoulides (2000), this approach is compatible with Popperian logic, which states that the primary interest of research is to reject models, rather than confirming them, since there is no scientific way of proving the validity of a proposed model. Therefore, there is a preference for dealing with models with a large number of degrees-of-freedom. According to Popperian logic, empirical science can only disconfirm and not confirm models. The goal of empirical science is to formulate theories that can be falsified, is facilitated by an application of the parsimony principle, because more parsimonious models that fit the data well, "has withstood a higher chance of rejection than a less parsimonious model" (Raykov and Marcoulides 2000, p. 37).

One primary difficulty with the $\chi^{2}$ test is that with large samples, there is a tendency to obtain very large $\chi^{2}$ values, which in turn are associated with very small $p$-values. If one, therefore, only uses the $p$-value as an indicator of model fit, there will be an artificial tendency to reject models that are only marginally inconsistent with the data. These limitations have led to a new plethora of other fit indices which all have their own merit.

In evaluating whether each step represents an improved fit over the preceding model, a whole range of fit measures should be considered (Raykov and Marcoulides, 2000). The most important measure is the $\chi^{2}$ statistic, with its accompanying degrees-offreedom. This measure is based on the deviations between the observed covariance matrix, and the model-implied covariance matrix. In the approach to imply increasingly more restrictions on model parameters, it is expected that the $\chi^{2}$ statistic and the degrees-of-freedom will also increase. Because the models are nested, it is possible to calculate the difference in $\chi^{2}$ value and the difference in the degrees-of-freedom to evaluate whether an imposed set of restrictions are tenable when compared to an alternative, less restricted model. In our case, the samples are very large, and this causes a tendency for the $\chi^{2}$ statistic to become very inflated, and then alternative measures of fit should also be relied upon. The non-normed fit index (NNFI), also known as the Tucker and Lewis index (TLI), the Incremental Fit Index (IFI), and the Comparative Fit Index (CFI), are all measures that have been developed to compensate for the artificial inflation of the $\chi^{2}$ statistic, although they are based on the $\chi^{2}$ value and takes model complexity into account. It is recommended that that TLI, IFI, and CFI all be above 0.95 for very good model fit. The RMSEA, developed by Browne and Cudeck (1993), has the advantage that it is reported with a $90 \%$ confidence interval, and when both the RMSEA and the upper bound of the $90 \%$ confidence interval are below 0.05 , and the lower bound of the RMSEA is considerably lower than 0.05 , the fit of the model can be regarded as very good. Another approach sometimes used is to consider the ratio of the $\chi^{2}$ statistic divided by the degree-of-freedom, and this ratio should ideally be less than 5 (Hu and Bentler, 1999; Raykov and Marcoulides, 2000).

\subsection{Findings for Malaysia and Singapore}

We followed the method summarised in Table 5, with the measures of fit in Table 6, which involves a series of increasingly restrictive hypotheses that are imposed on the model parameters in a certain sequence, using the default multiple group testing approach built into AMOS 17.0. Our approach was to first use the hierarchical testing procedure for the Singaporean and Malaysian samples alone, based on the guidelines of Steenkamp and Baumgartner (1998), since these two samples seemed much more similar than the other samples from our initial analyses.

Our approach was to include means and intercepts in our models. The first hypothesis, $\left(\mathrm{H}_{1}\right.$ in Table 5$)$ tests for configural or form invariance across the two countries and assumes the same positions for fixed and free parameters. $\mathrm{H}_{1}$ also allows the intercepts and mean vectors of the latent variables to be free across the two countries. In order to identify the model, one indicator per latent variable is set equal to unity, and the corresponding intercept term is set equal to zero. From the fit measures in Table 6 , it is clear that the initial model $\mathrm{H}_{1}$ fits the data very well, with $\mathrm{RMSEA}=0.024$, NNFI or $\mathrm{TLI}=0.983$, $\mathrm{IFI}=0.989$. The $\chi^{2}$ value is 390.9 with 84 degrees-of-freedom. Overall, the model in $\mathrm{H}_{1}$ presents a very good fit to the data.

The second hypothesis $\left(\mathrm{H}_{2}\right)$ imposes restrictions on parameters across the samples, and tests for equal factor loadings $\boldsymbol{\Lambda}_{x}$ of the exogenous latent variables and equal factor loadings $\boldsymbol{\Lambda}_{y}$ of the endogenous latent variables, as well as $\mathrm{H}_{1}$ simultaneously. The intercept terms and latent variable means are still allowed to be free across the two countries. This model also fits very well as shown in Table 6 under column $\mathrm{H}_{2}$, with $\mathrm{RMSEA}=0.024$, $\mathrm{TLI}=0.983$, IFI $=0.988$. The $\chi^{2}$ value is 419.5 with 92 degrees-offreedom. Since this model is plausible, it is valid to proceed with $\mathrm{H}_{3}$.

Hypothesis $\mathrm{H}_{3}$ imposes restrictions on the intercepts of the indicators of each latent variable and fitted the data well as can be seen in Table 6 in column $\mathrm{H}_{3}$ with $\mathrm{RMSEA}=0.026, \mathrm{TLI}=0.981$, $\mathrm{IFI}=0.985$. The $\chi^{2}$ value is 508.6 .9 with 100 degrees-of-freedom. Since this model, which implies scalar invariance, is plausible, it is valid ( Steenkamp and Baumgartner, 1998; Cheung and Rensvold, 2000) to compare the means of the latent variables as was done in $\mathrm{H}_{7}$.

Hypothesis $\mathrm{H}_{4}$ adds further constraints by focussing on the structural part of the model. It sets the gamma matrix, which represents all the effects of the independent variables to the dependent variables equal for the Malaysian and Singaporean samples. This represents the four arrows in Fig. 1, namely $b 1, b 2$, 
Table 5

Summary of hierarchical models tested to assess equivalence of the Malaysian and Singaporean samples.

\begin{tabular}{|c|c|}
\hline $\begin{array}{l}\text { Model } \mathrm{H}_{1} \text { : Same form or configural } \\
\text { invariance hypothesis also called } \\
\text { the unconstrained model }\end{array}$ & $\begin{array}{l}\text { Equivalent models of the same form } \\
\text { with parameters free across all } \\
\text { countries } \\
\text { Exogenous intercepts free, } \\
\text { endogenous intercepts free, } \\
\text { exogenous latent variable means free } \\
\text { and endogenous latent variable } \\
\text { intercepts free } \\
\text { *Note that in order to identify this } \\
\text { model, one indicator per latent } \\
\text { variable is fixed to unity, and the } \\
\text { corresponding intercept is fixed to } \\
\text { zero. }\end{array}$ \\
\hline $\begin{array}{l}\text { Model } \mathrm{H}_{2} \text { : Equal measurement } \\
\text { weights }\end{array}$ & $\begin{array}{l}\text { Model } \mathrm{H}_{1} \text { and all lambdas fixed. This } \\
\text { is a necessary model for metric } \\
\text { equivalence }\end{array}$ \\
\hline Model $\mathrm{H}_{3}$ : Equal intercepts & $\begin{array}{l}\text { Model } \mathrm{H}_{2} \text { and all measurement } \\
\text { intercepts fixed }\end{array}$ \\
\hline Model $\mathrm{H}_{4}$ : Equal structural weights & $\begin{array}{l}\text { Model } \mathrm{H}_{3} \text { and } b 1, b 2, b 3, b 4 \text {, and } b 5 \\
\text { fixed in Fig. } 1 \text {. }\end{array}$ \\
\hline Model $\mathrm{H}_{5}$ : Equal structural intercepts & $\begin{array}{l}\text { Model } \mathrm{H}_{4} \text { and the intercepts of feelings } \\
\text { and loyalty fixed }\end{array}$ \\
\hline Model $\mathrm{H}_{6}$ : Equal latent means & $\begin{array}{l}\text { Model } \mathrm{H}_{5} \text { with the means of the latent } \\
\text { variables finben, infben, feelings, and } \\
\text { loyalty constrained equal across } \\
\text { groups }\end{array}$ \\
\hline Model $\mathrm{H}_{7}$ : Partial invariance model & $\begin{array}{l}\text { Model } \mathrm{H}_{4} \text { with } b 3 \text { free, and the } \\
\text { intercept of feelings free. The equal } \\
\text { means restrictions for the four latent } \\
\text { variables were also relaxed to allow } \\
\text { these parameters to be unique across } \\
\text { the two countries. The variances of } \\
\text { finben and infben were constrained } \\
\text { equal, the covariance between finben } \\
\text { and infben was constrained equal, and } \\
\text { the variances of ee } 1 \text { and ee } 2 \text { were also } \\
\text { constrained equal. Error terms were } \\
\text { allowed to be free, since restricting } \\
\text { these are generally regarded as } \\
\text { unnecessary and overly restrictive } \\
\text { (Byrne, 1998). }\end{array}$ \\
\hline $\begin{array}{l}\text { Model } \mathrm{H}_{8} \text { : Model } \mathrm{H}_{7} \text { with } \\
\text { measurement weight of } \\
\text { endogenous variables relaxed }\end{array}$ & $\begin{array}{l}\text { Model } \mathrm{H}_{7} \text { with the measurement } \\
\text { weights of the endogenous variables } \\
\text { feelings and loyalty equal across } \\
\text { countries }\end{array}$ \\
\hline
\end{tabular}

$b 3$, and $b 4$. It also sets the matrix beta equal across the two samples, which represents the effects between the dependent variables in the model, in our case the single arrow $b 5$, pointing from feelings to loyalty. This model gives a very acceptable fit over $\mathrm{H}_{3}$, based on RMSEA $=0.025, \mathrm{TLI}=0.981, \mathrm{IFI}=0.985$. The $\chi^{2}$ value is 523.2 with 105 degrees-of-freedom. The latent variable means are still allowed to be free across the two countries.

Hypothesis $\mathrm{H}_{5}$ imposes further restrictions on the model, by forcing the structural intercepts of the latent variables feelings and loyalty equal. The latent variable means are still free for the two countries. The model in $\mathrm{H}_{5}$ is not a major improvement over $\mathrm{H}_{4}$, since the increase in $\chi^{2}$ value is rather big to 568.1 with 107 degrees-of-freedom, however, the other fit measures with $\mathrm{IFI}=0.983$, $\mathrm{TLI}=0.979, \mathrm{CFI}=0.983$, and $\mathrm{RMSEA}=0.026$ are still acceptable.

Hypothesis $\mathrm{H}_{6}$ uses the constraints in $\mathrm{H}_{5}$, and in addition also constrains the error variances to be equal across the two countries. This model states that the models are exactly equal for the two countries and that all parameters, except the latent variable means are equal across the two countries. When the model in $\mathrm{H}_{6}$ is compared to the previous models, it represents a remarkable drop in model fit considering several fit indices, even though they are still within acceptable norms. The RMSEA drops to 0.028 , IFI to 0.980 , TLI to 0.976 , and CFI to 0.980 .

The model in $\mathrm{H}_{7}$ represents a model where several parameters were kept equal across groups. However, some parameters were allowed to be free, in line with the idea of partial invariance, as described in considerable detail by Byrne et al. (1989). These parameters were identified by comparing evaluating model fit with the specific parameter fixed, and then by relaxing the parameter to be free across groups. Following this procedure, a more optimal model fit was achieved by allowing the means of the latent variables to be free across the two groups, as well as the structural parameter $b 3$, which represents the structural path between infben and feelings, and the structural intercept of feelings. We consider this model to be the most parsimonious model, which represents the observed data in an optimal way. This model is equivalent for both Singapore and Malaysia in terms of form invariance, metric and scalar invariance, and partially invariant in the structural part of the model. The means of the latent variables are not equal for the two countries. The estimated parameters and the resulting estimated total effects, direct and indirect effects of this model are reported in Tables 7 and 8 and are interpreted in depth.

In summary, for Singapore and Malaysia we have found evidence for a great deal of similarity on how benefits are perceived, and how they in turn affect feelings and loyalty behaviour. There are however subtle differences. At the measurement level, the model with equal measurement weights and equal intercepts of the measurement variables was plausible, which allows us to compare the model-implied means for the two samples.

Among the structural weights, all the structural weights, between finben and feelings (b1), finben and loyalty (b2), infben and loyalty (b4) as well as between feelings and loyalty (b5) could be constrained equal without too much loss in model fit. However, constraining the structural weight between infben and feelings ( $b 3$ ) equal across the two samples, resulted in a significant drop in model fit, and this structural weight was therefore left to be unique for each of the Malaysian and Singaporean samples. The intercept term for feelings was also allowed to be unique for each country.

In $\mathrm{H}_{7}$, we could also constrain the variances of finben and infben, as well as the covariance between finben and infben equal across the two samples, without too much loss in model fit. Similarly, the error variances of feelings (ee1) and loyalty (ee2) could be constrained equal across the two countries.

We were not interested in the complete invariance hypothesis, which constrains the error variances and error covariances equal across the groups. This hypothesis is generally regarded to be unrealistic and over-restricting (Byrne, 1998). The resulting maximum likelihood estimated model parameters are provided in Table 7.

All the estimated parameters are very highly significant, except the path $b 2$ between finben and loyalty, which is only significant at $\alpha=0.05$, and the path $b 4$ between infben and loyalty, which is only significant at $\alpha=0.001$. Perceived financial and information benefits have relatively small effects on loyalty, but seem to influence feelings, the mediator variable, which in turn has an effect on loyalty.

Although it is interesting to note few differences between Singapore and Malaysia, the implication of the single structural parameter that is unique across the two samples can only be fully appreciated when the effects are examined (Fox, 1980; Bollen, 1989). The total effect between two variables in a model is obtained by multiplying the estimated coefficients between variables. For example, consider the basic model in Fig. 1. The direct effect between finben and loyalty, is the structural regression coefficient $b 2$ in Fig. 1 . The indirect effect between 
Table 6

Measures of fit for the Singaporean and the Malaysian samples.

\begin{tabular}{|c|c|c|c|c|c|c|c|c|c|}
\hline \multicolumn{2}{|l|}{ Model } & $\begin{array}{l}\text { Uncon- } \\
\text { strained }\end{array}$ & $\begin{array}{l}\text { Measure- } \\
\text { ment } \\
\text { weights } \\
\mathrm{H}_{2}\end{array}$ & $\begin{array}{l}\text { Measure- } \\
\text { ment } \\
\text { intercepts } \\
\mathrm{H}_{3}\end{array}$ & $\begin{array}{l}\text { Structural } \\
\text { weights }\end{array}$ & $\begin{array}{l}\text { Structural } \\
\text { intercepts }\end{array}$ & $\begin{array}{l}\text { Structural } \\
\text { intercepts } \\
\text { and means } \\
\mathrm{H}_{6}\end{array}$ & $\begin{array}{l}\text { Model with partial } \\
\text { invariance in } \\
\text { structural weight } \\
\text { and intercept, } \\
\text { means free } \\
\mathrm{H}_{7}\end{array}$ & $\begin{array}{l}\text { Model }_{7} \text { with } \\
\text { indicator } \\
\text { weights of } \\
\text { feeling and } \\
\text { loyalty free } \\
\mathrm{H}_{8}\end{array}$ \\
\hline & $\begin{array}{l}\text { Required for } \\
\text { acceptable fit } \\
\text { and } \\
\text { parsimony }\end{array}$ & $\begin{array}{l}\text { Required } \\
\text { for } \\
\text { meaningful } \\
\text { compari- } \\
\text { sons across } \\
\text { countries }\end{array}$ & $\begin{array}{l}\text { Required in } \\
\text { terms of } \\
\text { metric } \\
\text { equivalence }\end{array}$ & $\begin{array}{l}\text { Required in } \\
\text { terms of } \\
\text { scalar } \\
\text { equivalence }\end{array}$ & $\begin{array}{l}\text { Model } \\
\text { rejected - } \\
\text { too } \\
\text { restrictive }\end{array}$ & $\begin{array}{l}\text { Model } \\
\text { rejected - } \\
\text { too } \\
\text { restrictive }\end{array}$ & $\begin{array}{l}\text { Model } \\
\text { rejected - } \\
\text { too } \\
\text { restrictive }\end{array}$ & $\begin{array}{l}\text { Plausible most } \\
\text { parsimonious } \\
\text { model }\end{array}$ & $\begin{array}{l}\text { Only tested } \\
\text { for the sake } \\
\text { of interest }\end{array}$ \\
\hline NPAR & $\begin{array}{l}\text { Few } \\
\text { parameters }\end{array}$ & 96 & 88 & 80 & 75 & 73 & 71 & 70 & 76 \\
\hline CMIN & $\chi^{2}$ small & 390.9 & 419.5 & 508.6 & 523.2 & 568.1 & 655.0 & 545.2 & 473.4 \\
\hline DF & $\begin{array}{l}\text { More degrees- } \\
\text { of-freedom }\end{array}$ & 84 & 92 & 100 & 105 & 107 & 109 & 110 & 104 \\
\hline CMIN/DF & $<5.0$ & 4.654 & 4.560 & 5.086 & 4.983 & 5.310 & 6.009 & 4.957 & 4.553 \\
\hline \multicolumn{3}{|c|}{ Models compared in $\chi^{2}$ difference test: } & $\mathrm{H}_{2}-\mathrm{H}_{1}$ & $\mathrm{H}_{3}-\mathrm{H}_{2}$ & $\mathrm{H}_{4}-\mathrm{H}_{3}$ & $\mathrm{H}_{5}-\mathrm{H}_{4}$ & $\mathrm{H}_{6}-\mathrm{H}_{5}$ & $\mathrm{H}_{7}-\mathrm{H}_{3}$ & $\mathrm{H}_{7}-\mathrm{H}_{8}$ \\
\hline CMIN diff & $\chi^{2}$ difference & & 28.6 & 89.1 & 14.6 & 44.9 & 86.9 & 36.6 & 71.8 \\
\hline diff $d f$ & $\begin{array}{l}\text { Difference in } \\
\text { df }\end{array}$ & & 8 & 8 & 5 & 2 & 2 & 10 & 6 \\
\hline$p$-Value & $\begin{array}{l}p \text {-Value of } \\
\text { CMIN diff }\end{array}$ & & 0.0004 & 0.0000 & 0.0122 & 0.0000 & 0.0000 & 0.0001 & 0.0000 \\
\hline IFI & $>0.95$ & 0.989 & 0.988 & 0.985 & 0.985 & 0.983 & 0.980 & 0.984 & 0.987 \\
\hline TLI & $>0.95$ & 0.983 & 0.983 & 0.981 & 0.981 & 0.979 & 0.976 & 0.981 & 0.983 \\
\hline CFI & $>0.95$ & 0.989 & 0.988 & 0.985 & 0.985 & 0.983 & 0.980 & 0.984 & 0.987 \\
\hline PRATIO & Larger better & 0.636 & 0.697 & 0.758 & 0.795 & 0.811 & 0.826 & 0.833 & 0.788 \\
\hline PNFI & Larger better & 0.627 & 0.686 & 0.744 & 0.781 & 0.794 & 0.806 & 0.817 & 0.774 \\
\hline PCFI & Larger better & 0.629 & 0.689 & 0.746 & 0.783 & 0.797 & 0.809 & 0.82 & 0.777 \\
\hline RMSEA & $<0.05$ & 0.024 & 0.024 & 0.026 & 0.025 & 0.026 & 0.028 & 0.025 & 0.024 \\
\hline LO 90 & $<0.05$ & 0.022 & 0.022 & 0.023 & 0.023 & 0.024 & 0.026 & 0.023 & 0.022 \\
\hline HI 90 & $<0.05$ & 0.027 & 0.026 & 0.028 & 0.027 & 0.028 & 0.030 & 0.027 & 0.027 \\
\hline
\end{tabular}

finben and loyalty is the product of $b 1$ and $b 5$ in Fig. 1 . The total effect between finben and loyalty is the sum of direct and indirect effects. All the effects in our model for Malaysia and Singapore are presented in Table 8, and from the total effects, the eventual result of the single unique parameter is more obvious.

Although the information benefits have a significantly stronger effect on the feelings of Malaysian shoppers than Singaporean shoppers, 0.234 for Malaysian, vs. 0.163 for Singaporean shoppers, the resulting total effect of information benefits on actual loyalty behaviours is only slightly different, under the assumption (due to our model restriction) that the direct effect between feelings and loyalty remain constant across the two countries. From our model we can infer that although information benefits have a slightly stronger effect in the Malaysian sample with respect to frequency of use and frequency of carrying the card, the real difference is the stronger total effect in recommending the card to others. Our model implies that on average, if we could hold everything else in the model constant, except for allowing a unit increase (on a scale from 1 to 5 ) in perceived information benefits, the result in recommending the card to others would increase by 0.212 for the Malaysians and by 0.174 for the Singaporeans (measured on a scale from 1 to 4 ).

We also considered the argument that our model, which restricted the measurement weights equal on the endogenous variables feelings and loyalty, induces an artificial restriction on the indicators of loyalty behaviour. We therefore considered a model $\left(\mathrm{H}_{8}\right)$ where the measurement weights of feelings and loyalty are allowed to be free, to see how freeing these parameters changed the final total effects between benefits, feelings, and loyalty behaviours. We only report the estimated effects in Table 9.
As shown in Table 9, the total effect of perceived information benefits on actual loyalty behaviours did not change much from the previous model $\left(\mathrm{H}_{7}\right)$ with effects in Table 8. Although feelings were affected more for the Malaysian sample than the Singaporean sample, as shown in the shaded area in Table 9, the resulting effects of feelings on loyalty behaviours were almost identical for the two samples.

Since model $\left(\mathrm{H}_{3}\right)$ in the hierarchical test procedure was tenable for the Singaporean and Malaysian samples, it is valid to compare the estimated model-implied means across these two countries shown in Table 10, which show that the Malaysian sample was on average slightly more positive on all the indicator items.

When the means of the latent variables finben, infben, feelings and loyalty are considered, the Malaysians were just slightly more positive about the financial benefits of the card (difference 0.1 ) and a bit more positive about the information benefits (difference 0.2 ). The feelings of Malaysians were 0.24 points higher than those of the Singaporeans, and yet the difference in average loyalty was only 0.04 . It seems, therefore, that although Malaysians perceive benefits on average higher than Singaporeans, and value information benefits slightly more than financial benefits, and although these perceived benefits resulted in higher levels of emotional feelings for Malaysians, the average loyalty behaviours remained very similar. This is slightly contrary to what one would expect, and a possible explanation for this result, is that loyalty behaviours are certainly influenced by affordability, and even though Malaysians feel more positive about the benefits, financial constraints may inhibit actual behaviours. Another explanation could be that Malaysians are emotionally more influenced than Singaporeans. 
Table 7

Maximum likelihood estimated model parameters ${ }^{\mathrm{a}}$ (unstandardised).

\begin{tabular}{|c|c|c|c|c|c|}
\hline \multicolumn{3}{|c|}{ Regression Weights } & \multirow{2}{*}{$\begin{array}{l}\text { Singapore } \\
\text { Estimate }\end{array}$} & \multirow{2}{*}{$\begin{array}{l}\text { Malaysia } \\
\text { Estimate }\end{array}$} & \multirow[t]{2}{*}{$p$} \\
\hline \multicolumn{3}{|c|}{ Measurement weights } & & & \\
\hline Finben & $\rightarrow$ & B1 & 1 & 1 & \\
\hline Finben & $\rightarrow$ & B2 & $1.413^{\mathrm{b}}$ & 1.413 & $* * *$ \\
\hline Finben & $\rightarrow$ & B3 & 1.243 & 1.243 & $* * *$ \\
\hline Infben & $\rightarrow$ & B7 & 1 & 1 & \\
\hline Infben & $\rightarrow$ & B8 & 0.818 & 0.818 & $* * *$ \\
\hline Feelings & $\rightarrow$ & $\mathrm{F} 4$ & 1 & 1 & \\
\hline Feelings & $\rightarrow$ & F5 & 1.002 & 1.002 & $* * *$ \\
\hline Feelings & $\rightarrow$ & F7 & 0.978 & 0.978 & $* * *$ \\
\hline Feelings & $\rightarrow$ & F8 & 1.048 & 1.048 & $* * *$ \\
\hline Loyalty & $\rightarrow$ & Usefreq & 1 & 1 & \\
\hline Loyalty & $\rightarrow$ & Carrfreq & 1.446 & 1.446 & $* * *$ \\
\hline Loyalty & $\rightarrow$ & Recomm & 3.769 & 3.769 & $* * *$ \\
\hline \multicolumn{6}{|c|}{ Structural weights } \\
\hline b1: Finben & $\rightarrow$ & Feelings & 0.714 & 0.714 & $* * *$ \\
\hline b2: Finben & $\rightarrow$ & Loyalty & 0.027 & 0.027 & 0.046 \\
\hline$b 3$ : Infben & $\rightarrow$ & Feeling & $0.163^{c}$ & 0.234 & $* * *$ \\
\hline b4: Infben & $\rightarrow$ & Loyalty & 0.022 & 0.022 & 0.001 \\
\hline b5: Feelings & $\rightarrow$ & Loyalty & 0.146 & 0.146 & $* * *$ \\
\hline \multicolumn{6}{|l|}{ Covariances } \\
\hline Finben & $\leftrightarrow$ & Infben & 0.311 & 0.311 & $* * *$ \\
\hline \multicolumn{6}{|l|}{ Correlations $^{\mathrm{d}}$} \\
\hline Finben & $\leftrightarrow$ & Infben & 0.729 & 0.729 & \\
\hline \multicolumn{6}{|l|}{ Variances } \\
\hline & & FINBEN & 0.249 & 0.249 & $* * *$ \\
\hline & & InfbenNFBEN & 0.731 & 0.731 & $* * *$ \\
\hline & & ee1 & 0.402 & 0.402 & \\
\hline & & ee2 & 0.007 & 0.007 & \\
\hline
\end{tabular}

${ }^{\text {a }}$ For the sake of simplicity, measurement error parameters are not reported, but they are unique for the two countries.

b Parameters in normal text are constrained equal across the two countries.

c Parameters in bold italics are unique across the two countries.

${ }^{\mathrm{d}}$ Correlation reported from standardised solution.

\subsection{Hong Kong, Taiwan, and Thailand}

When the hierarchical testing method in Table 11 was followed, the procedure quickly broke down, so that very few similarities between these three countries could be found. When the measurement intercepts were constrained equal, the model fit was severely effected. The best plausible model we could find was a model with only a few constraints. It was however still very interesting to compare the models across the five countries.

The first hypothesis ( $\mathrm{H}_{1}$ in Tables 11 and 12$)$, tests for configural or form invariance across three countries. It assumes the same positions for fixed and free parameters, and also allows the intercepts and mean vectors of the latent variables to be free across the three countries. In order to identify the model, one indicator per latent variable is set equal to unity, and the corresponding intercept term is set equal to zero. From the fit measures in Table 12, it is clear that this model fits the data very well, with $\mathrm{RMSEA}=0.017, \mathrm{TLI}=0.986$, and $\mathrm{IFI}=0.991$. The $\chi^{2}$ statistic is 493.3 with 126 degrees-of-freedom. Overall, this model presents a very good fit to the data, which means that our model is a plausible explanation of the relationships between financial and information benefits towards feelings and loyalty.

The second model $\left(\mathrm{H}_{2}\right)$ imposes restrictions on parameters across the samples and constrains the measurement weights for exogenous and endogenous latent variables equal. The intercept terms and latent variable means are still allowed to be free across the three countries. This model also fits very well as shown in Table 12 under column $\mathrm{H}_{2}$, with $\mathrm{RMSEA}=0.018$, NNFI $=0.984$, and $\mathrm{IFI}=0.989$. The $\chi^{2}$ statistic is 594.0 with 142 degrees-of-freedom. This model still fits the data very well when most fit measures are considered, and seem to be a reasonable approximation of the data.

The third hypothesis $\left(\mathrm{H}_{3}\right)$ imposes restrictions on the intercepts of the indicators to each latent variable. Although most fit measures are still within acceptable norms, the tremendous increase in the $\chi^{2}$ value to 2252.7 with 158 degrees-of-freedom. The other fit measures are $\mathrm{RMSEA}=0.037, \mathrm{TLI}=0.935, \mathrm{IFI}=0.948$. Since this model, which implies scalar invariance, is not plausible, it is invalid to compare the means of the latent variables (Steenkamp and Baumgartner, 1998; Cheung and Rensvold, 2000).

After the model in $\mathrm{H}_{3}$, several sequences were followed to estimate increasingly restrictive models using the partial invariance principle. $\mathrm{H}_{4}$ is our final, most parsimonious model, with restrictions that were tenable. Since $\mathrm{H}_{4}$ is less restricted than $\mathrm{H}_{2}$, it is compare to $\mathrm{H}_{1}$ in the $\chi^{2}$ difference test. This model has very few restrictions: only the indicator weights of finben and infben were restricted equal across groups, and among the structural weights, only the weights b2, b3, b4, and b5 between Hong Kong and Taiwan were restricted equal. All other parameters were allowed to be free. Since the equal indicator intercept hypothesis was not tenable, we do not report model-implied mean estimates, as it would be invalid to compare these. However, it is still very informative to compare the estimated parameters in Table 13 across the three countries, as well as the direct, indirect, and total effects as shown in Table 14.

The estimated parameters as well as the scaling indicators (the regression weights that were constrained equal to 1 for the purpose of model identification) of model $\mathrm{H}_{4}$ in Table 13 postulates that both benefit latent variables, finben and infben are indicated with equal measurement weights by their corresponding indicator variables across all three countries. A unit change in the latent variable of how benefits are perceived has an equal increment on how individuals in each of the three countries adjust their response to the observed items.

A very interesting aspect in our model for these three countries is the substantial higher correlation between financial benefits and information benefits across the three samples, when compared to Singapore and Malaysia. The correlation between these two variables was 0.73 for Singapore and Malaysia, 0.82 for Hong Kong, 0.90 for Taiwan, and 0.96 for Thailand.

In our final model, it was also plausible to constrain the measurement weights $b 2, b 3, b 4$, and $b 5$ equal across the Hong Kong and Taiwanese samples. The weight $b 2$, from finben to loyalty was insignificant for both these two countries, which implies that loyalty is not directly affected by perceived financial benefits, but is mediated by feelings. Further, although information benefits have an equal effect on feelings in Hong Kong and Taiwan, financial benefits have a stronger effect on feelings than information benefits in both samples. In contrast, in the Thailand sample, information benefits have an insignificant effect on feelings or loyalty. This is further confirmed by the high correlation between information benefits and financial benefits for Thailand, almost as if Thais saw financial benefits and information benefits as the same construct. As if they say "If benefits are not financial, they are irrelevant".

The effect of financial benefits on feelings is 33\% stronger for the Hong Kong sample than for the Taiwanese sample (0.755/ $0.566=1.33)$. For the Thais, the effect of financial benefits on feelings is twice as strong as for Taiwan $(1.185 / 0.566=2.094)$, and roughly $50 \%$ stronger than for Hong Kong $(1.185 / 0.755=1.570)$.

Even though the effects of financial benefits are so different on the mediating variable, the resulting effect on loyalty as a latent variable across the three countries seems to be quite similar. The structural coefficient b5 form feelings to loyalty is equal to 0.140 for the Hong Kong and Taiwanese samples, and only slightly stronger for the Thailand sample at 0.177 . 
Table 8

Estimated total, direct, and indirect effects

\begin{tabular}{|c|c|c|c|c|c|c|c|c|}
\hline & & & \multicolumn{2}{|c|}{ Total effects } & \multicolumn{2}{|c|}{ Direct effects } & \multicolumn{2}{|c|}{ Indirect effects } \\
\hline & & & Singapore & Malaysia & Singapore & Malaysia & Singapore & Malaysia \\
\hline Finben & $\rightarrow$ & B1 & 1.000 & 1.000 & 1.000 & 1.000 & & \\
\hline Finben & $\rightarrow$ & B2 & $1.413^{\mathrm{a}}$ & 1.413 & 1.413 & 1.413 & & \\
\hline Finben & $\rightarrow$ & B3 & 1.243 & 1.243 & 1.243 & 1.243 & & \\
\hline Finben & $\rightarrow$ & Feelings & 0.714 & 0.714 & 0.714 & 0.714 & & \\
\hline Finben & $\rightarrow$ & $\mathrm{F} 4$ & 0.714 & 0.714 & & & 0.714 & 0.714 \\
\hline Finben & $\rightarrow$ & F5 & 0.716 & 0.716 & & & 0.716 & 0.716 \\
\hline Finben & $\rightarrow$ & F7 & 0.699 & 0.699 & & & 0.699 & 0.699 \\
\hline Finben & $\rightarrow$ & F8 & 0.748 & 0.748 & & & 0.748 & 0.748 \\
\hline Finben & $\rightarrow$ & Loyalty & 0.131 & 0.131 & 0.027 & 0.027 & 0.104 & 0.104 \\
\hline Finben & $\rightarrow$ & Usefreq & 0.131 & 0.131 & & & 0.131 & 0.131 \\
\hline Finben & $\rightarrow$ & Carrfreq & 0.189 & 0.189 & & & 0.189 & 0.189 \\
\hline Finben & $\rightarrow$ & Recomm & 0.494 & 0.494 & & & 0.494 & 0.494 \\
\hline Infben & $\rightarrow$ & B7 & 1.000 & 1.000 & & & & \\
\hline Infben & $\rightarrow$ & B8 & 0.818 & 0.818 & & & & \\
\hline Infben & $\rightarrow$ & $\mathrm{F} 4$ & $0.163^{b}$ & 0.234 & & & 0.163 & 0.234 \\
\hline Infben & $\rightarrow$ & F5 & 0.163 & 0.234 & & & 0.163 & 0.234 \\
\hline Infben & $\rightarrow$ & F7 & 0.159 & 0.229 & & & 0.159 & 0.229 \\
\hline Infben & $\rightarrow$ & F8 & 0.171 & 0.245 & & & 0.171 & 0.245 \\
\hline Infben & $\rightarrow$ & Feelings & 0.163 & 0.234 & 0.163 & 0.234 & & \\
\hline Infben & $\rightarrow$ & Loyalty & 0.046 & 0.056 & 0.022 & 0.022 & 0.024 & 0.034 \\
\hline Infben & $\rightarrow$ & Usefreq & 0.046 & 0.056 & & & 0.046 & 0.056 \\
\hline Infben & $\rightarrow$ & Carrfreq & 0.067 & 0.082 & & & 0.067 & 0.082 \\
\hline Infben & $\rightarrow$ & Recomm & 0.174 & 0.212 & & & 0.174 & 0.212 \\
\hline Feelings & $\rightarrow$ & F4 & 1.000 & 1.000 & 1.000 & 1.000 & & \\
\hline Feelings & $\rightarrow$ & F5 & 1.002 & 1.002 & 1.002 & 1.002 & & \\
\hline Feelings & $\rightarrow$ & F7 & 0.978 & 0.978 & 0.978 & 0.978 & & \\
\hline Feelings & $\rightarrow$ & F8 & 1.048 & 1.048 & 1.048 & 1.048 & & \\
\hline Feelings & $\rightarrow$ & Loyalty & 0.146 & 0.146 & 0.146 & 0.146 & & \\
\hline Feelings & $\rightarrow$ & Usefreq & 0.146 & 0.146 & & & 0.146 & 0.146 \\
\hline Feelings & $\rightarrow$ & Carrfreq & 0.210 & 0.210 & & & 0.210 & 0.210 \\
\hline Feelings & $\rightarrow$ & Recomm & 0.549 & 0.549 & & & 0.549 & 0.549 \\
\hline Loyalty & $\rightarrow$ & Usefreq & 1.000 & 1.000 & 1.000 & 1.000 & & \\
\hline Loyalty & $\rightarrow$ & Carrfreq & 1.446 & 1.446 & 1.446 & 1.446 & & \\
\hline Loyalty & $\rightarrow$ & Recomm & 3.769 & 3.769 & 3.769 & 3.769 & & \\
\hline
\end{tabular}

a Estimated effects in normal text are due to parameters constrained equal across the two countries in Table 7.

${ }^{b}$ Estimated effects in bold italics are unique across the two countries, due to unique parameter estimates in Table 7.

It is also interesting to see how actual behaviours are indicated differently in the three countries. Our loyalty variable was scaled to 'mirror' frequency of use (due to scaling indicator constrained to one for model identification purposes). The scaling indicator is chosen arbitrarily. In our case, it allows for some interesting interpretations. In our model, the interpretation is that if "Usefreq" is used as a direct reflection of loyalty, the Hong Kong sample will be on average be 1.45 times likely to carry the card with them, and 3.262 times as likely to recommend the card, compared to how often they actually use the card. The Taiwanese sample will be 1.73 times as likely to carry the card and 2.75 times as likely to recommend the card, compared to how often they use the card. The Thailand sample will be 1.54 times more likely to carry the card than use the card, and about 3.6 times as likely to recommend the card.

The findings lead one to think that if frequency of use is used as "barometer" of loyalty (through the scaling indicator fixed at unity), all three groups are more likely to carry the card, which may signal intention, and much more likely to recommend the card to others. It is as if the data suggest that if loyalty cannot be displayed by actual use of the card, shoppers would 'compensate' through alternative loyalty behaviours by approximately $50-70 \%$ with intentions (by carrying the card), and compensate about $270-350 \%$ by recommending the card to others. Almost as if saying, although lack of financial means inhibit us to use the card, "if we cannot vote with dollars, we will vote quietly by carrying the card, but shout out our loyalty by recommending the card to others".
A limitation in our samples from Hong Kong, Taiwan, and Thailand is that intercept invariance was very strongly rejected. It is therefore not possible to compare the model-implied means across the three countries. "If a construct displays intercept noninvariance, the attempt to compare the latent means of that construct across groups must be abandoned" (Cheung and Rensvold, 2000, p. 200). For the sake of completeness the estimated intercepts are shown in Table 15.

What have we learnt from the model fitted to the Hong Kong, Taiwan, and Thailand data? First, that these countries make very little distinction between financial benefits and information benefits, due to the high correlation between financial benefits and information benefits. Second, form invariance suggests that the relationships between financial benefits, information benefits, feelings, and loyalty are similar and are indicated by the same items across the three countries. Third, the relative importance of these indicators as reflected in the factor loadings (factorial invariance), is not significantly different across the countries. Fourth, neither financial benefits nor information benefits have a direct impact on loyalty, but the impact is through the mediator variable, feelings. Fifth, the influence of financial benefits on feelings was much stronger than the influence of information benefits on feelings. In fact, the influence of information benefits on feelings was insignificant for the Thailand sample. Finally, the presence of response style differences between the countries is strongly suggested, but not proved, based on the rejection of the overall intercept invariance hypothesis. The loyalty items and the feeling items are therefore suspected to be interpreted very differently across the three cultural groups/countries. Figs. 3-7. 
Table 9

Estimated effects for model $\mathrm{H}_{8}$ with measurement weights of feelings and loyalty free.

\begin{tabular}{|c|c|c|c|c|c|c|c|c|}
\hline & & & \multicolumn{2}{|c|}{ Total effects } & \multicolumn{2}{|c|}{ Direct effects } & \multicolumn{2}{|c|}{ Indirect effects } \\
\hline & & & Singapore & Malaysia & Singapore & Malaysia & Singapore & Malaysia \\
\hline Finben & $\rightarrow$ & B1 & 1.000 & 1.000 & 1.000 & 1.000 & & \\
\hline Finben & $\rightarrow$ & B2 & $1.413^{\mathrm{a}}$ & 1.413 & 1.413 & 1.413 & & \\
\hline Finben & $\rightarrow$ & B3 & 1.243 & 1.243 & 1.243 & 1.243 & & \\
\hline Finben & $\rightarrow$ & Feelings & 0.712 & 0.712 & 0.712 & 0.712 & & \\
\hline Finben & $\rightarrow$ & F4 & 0.712 & 0.712 & & & 0.712 & 0.712 \\
\hline Finben & $\rightarrow$ & F5 & $0.743^{b}$ & 0.715 & & & 0.743 & 0.715 \\
\hline Finben & $\rightarrow$ & F7 & 0.692 & 0.697 & & & 0.692 & 0.697 \\
\hline Finben & $\rightarrow$ & F8 & 0.755 & 0.744 & & & 0.755 & 0.744 \\
\hline Finben & $\rightarrow$ & Loyalty & 0.128 & 0.128 & 0.024 & 0.024 & 0.104 & 0.104 \\
\hline Finben & $\rightarrow$ & Usefreq & 0.128 & 0.128 & & & 0.128 & 0.128 \\
\hline Finben & $\rightarrow$ & Carrfreq & 0.179 & 0.181 & & & 0.179 & 0.181 \\
\hline Finben & $\rightarrow$ & Recomm & 0.496 & 0.492 & & & 0.496 & 0.492 \\
\hline Infben & $\rightarrow$ & B7 & 1.000 & 1.000 & 1.000 & 1.000 & & \\
\hline Infben & $\rightarrow$ & B8 & 0.818 & 0.818 & 0.818 & 0.818 & & \\
\hline Infben & $\rightarrow$ & Feelings & 0.154 & 0.235 & 0.154 & 0.235 & & \\
\hline Infben & $\rightarrow$ & F4 & 0.154 & 0.235 & & & 0.154 & 0.235 \\
\hline Infben & $\rightarrow$ & F5 & 0.161 & 0.237 & & & 0.161 & 0.237 \\
\hline Infben & $\rightarrow$ & F7 & 0.150 & 0.231 & & & 0.150 & 0.231 \\
\hline Infben & $\rightarrow$ & F8 & 0.164 & 0.246 & & & 0.164 & 0.246 \\
\hline Infben & $\rightarrow$ & Loyalty & 0.045 & 0.057 & 0.023 & 0.023 & 0.022 & 0.034 \\
\hline Infben & $\rightarrow$ & Usefreq & 0.045 & 0.057 & & & 0.045 & 0.057 \\
\hline Infben & $\rightarrow$ & Carrfreq & 0.063 & 0.081 & & & 0.063 & 0.081 \\
\hline Infben & $\rightarrow$ & Recomm & 0.174 & 0.218 & & & 0.174 & 0.218 \\
\hline Feelings & $\rightarrow$ & $\mathrm{F} 4$ & 1.000 & 1.000 & 1.000 & 1.000 & & \\
\hline Feelings & $\rightarrow$ & F5 & 1.044 & 1.005 & 1.044 & 1.005 & & \\
\hline Feelings & $\rightarrow$ & F7 & 0.972 & 0.979 & 0.972 & 0.979 & & \\
\hline Feelings & $\rightarrow$ & F8 & 1.061 & 1.046 & 1.061 & 1.046 & & \\
\hline Feelings & $\rightarrow$ & Loyalty & 0.146 & 0.146 & 0.146 & 0.146 & & \\
\hline Feelings & $\rightarrow$ & Usefreq & 0.146 & 0.146 & & & 0.146 & 0.146 \\
\hline Feelings & $\rightarrow$ & Carrfreq & 0.204 & 0.206 & & & 0.204 & 0.206 \\
\hline Feelings & $\rightarrow$ & Recomm & 0.565 & 0.560 & & & 0.565 & 0.560 \\
\hline Loyalty & $\rightarrow$ & Usefreq & 1.000 & 1.000 & 1.000 & 1.000 & & \\
\hline Loyalty & $\rightarrow$ & Carrfreq & 1.397 & 1.416 & 1.397 & 1.416 & & \\
\hline Loyalty & $\rightarrow$ & Recomm & 3.873 & 3.839 & 3.873 & 3.839 & & \\
\hline
\end{tabular}

a Estimated effects in normal text are due to parameters estimates constrained equal between the two countries.

b Estimated effects in bold italics are unique between the two countries.

Table 10

Maximum likelihood estimated model implied intercepts and means.

\begin{tabular}{|c|c|c|c|c|}
\hline & \multicolumn{2}{|l|}{ Intercepts } & \multicolumn{2}{|c|}{ Model implied means } \\
\hline & Singapore & Malaysia & Singapore & Malaysia \\
\hline B1 & $0.000^{\mathrm{a}}$ & 0.000 & 3.89 & 3.99 \\
\hline B2 & $-2.215^{b}$ & -2.125 & 3.37 & 3.51 \\
\hline B3 & -1.039 & -1.039 & 3.80 & 3.92 \\
\hline B7 & 0.000 & 0.000 & 3.71 & 3.91 \\
\hline B8 & 0.898 & 0.898 & 3.93 & 4.10 \\
\hline $\mathrm{F} 4$ & $0.000^{\mathrm{a}}$ & 0.000 & 2.89 & 3.13 \\
\hline F5 & 0.600 & 0.600 & 3.49 & 3.74 \\
\hline F7 & -0.126 & -0.126 & 2.70 & 2.94 \\
\hline F8 & -0.224 & -0.224 & 2.80 & 3.06 \\
\hline Usefreq & $0.000^{\mathrm{a}}$ & 0.000 & 3.71 & 3.75 \\
\hline Carrfreq & -1.829 & -1.829 & 3.53 & 3.60 \\
\hline Recomm & -11.798 & -11.798 & 2.18 & 2.34 \\
\hline Finben & - & - & 3.89 & 3.99 \\
\hline Infben & - & - & 3.71 & 3.91 \\
\hline Feelings & $-0.495^{\mathrm{c}}$ & -0.630 & 2.89 & 3.13 \\
\hline Loyalty & 3.101 & 3.101 & 3.71 & 3.75 \\
\hline
\end{tabular}

${ }^{a}$ In order to identify the model, the intercepts corresponding to the scaling indicator that was constrained equal to one, was set equal to zero.

${ }^{\mathrm{b}}$ Estimated intercepts in normal text constrained equal across the two countries.

${ }^{\mathrm{c}}$ Estimated intercepts in bold italics unique across the two countries.

\section{Conclusion}

Investment in consumer loyalty programmes is substantial, global, and is rapidly expanding. To substantiate the investments
Table 11

Summary of hierarchical models tested to assess equivalence of the Hong Kong Taiwan, and Thailand samples.

\begin{tabular}{|c|c|}
\hline $\begin{array}{l}\text { Model } \mathrm{H}_{1} \text { : same form or configural } \\
\text { invariance hypothesis also called } \\
\text { the unconstrained model }\end{array}$ & $\begin{array}{l}\text { Equivalent models of the same form } \\
\text { with parameters free across all } \\
\text { countries } \\
\text { Exogenous intercepts free, endogenous } \\
\text { intercepts free, exogenous latent } \\
\text { variable means free and endogenous } \\
\text { latent variable intercepts free } \\
\text { *Note that in order to identify this } \\
\text { model, one indicator per latent variable } \\
\text { is fixed to unity, and the corresponding } \\
\text { intercept is fixed to zero. }\end{array}$ \\
\hline $\begin{array}{l}\text { Model } \mathrm{H}_{2} \text { : equal measurement } \\
\text { weights }\end{array}$ & $\begin{array}{l}\text { Model } \mathrm{H}_{1} \text { and all lambdas fixed. This is a } \\
\text { necessary model for metric equivalence }\end{array}$ \\
\hline Model $\mathrm{H}_{3}$ : equal intercepts & $\begin{array}{l}\text { Model } \mathrm{H}_{2} \text { and all measurement } \\
\text { intercepts fixed }\end{array}$ \\
\hline Model $\mathrm{H}_{4}$ : equal structural weights & $\begin{array}{l}\text { Only lambdas of benefit items fixed } \\
\text { across all three countries; and } b 2, b 3, b 4 \\
\text { and } b 5 \text { fixed in Fig. } 1 \text {, only between } \\
\text { Hong Kong and Taiwan. }\end{array}$ \\
\hline
\end{tabular}

made, marketers need to understand whether these investments provide positive returns. While the adoption rate of loyalty cards has been staggering, many consumers claim that loyalty cards do not influence their shopping behaviour. Also, due to cultural influences, loyalty programmes that work in one country may not necessarily work in another. Research has shown that Asians may have behaviours, loyalty attitudes, and other consumer attitudes 
Table 12

Measures of fit for the Hong Kong, Taiwan, and Thailand samples.

\begin{tabular}{|c|c|c|c|c|c|}
\hline & & $\mathrm{H}_{1}$ & $\mathrm{H}_{2}$ & $\begin{array}{l}\text { Measurement } \\
\text { intercepts } \\
\mathrm{H}_{3}\end{array}$ & $\begin{array}{l}\text { Benefit measurement weights } \\
\text { equal, all intercepts free, } \\
\text { structural paths } b 2, b 3, b 4, b 5 \\
\text { between Hong Kong and } \\
\text { Taiwan equal, all else } \\
\text { unconstrained } \\
\mathrm{H}_{4}\end{array}$ \\
\hline & $\begin{array}{l}\text { Required for } \\
\text { acceptable fit and } \\
\text { parsimony }\end{array}$ & $\begin{array}{l}\text { Required for } \\
\text { meaningful } \\
\text { comparisons across } \\
\text { countries }\end{array}$ & $\begin{array}{l}\text { Required in terms of } \\
\text { metric equivalence }\end{array}$ & $\begin{array}{l}\text { Required in terms of } \\
\text { scalar equivalence. } \\
\text { Model rejected Fit } \\
\text { inadequate }\end{array}$ & $\begin{array}{l}\text { Partial invariance model with } \\
\text { very few restrictions }\end{array}$ \\
\hline NPAR & Few parameters & 144 & 128 & 112 & 134 \\
\hline CMIN & $\chi^{2}$ small & 493.3 & 594.0 & 2252.7 & 542.6 \\
\hline $\mathrm{DF}$ & $\begin{array}{l}\text { More degrees-of- } \\
\text { freedom }\end{array}$ & 126 & 142 & 158 & 136 \\
\hline CMIN/DF & $<5.0$ & 3.915 & 4.183 & 14.257 & 3.989 \\
\hline \multicolumn{3}{|c|}{ Models compared using $\chi^{2}$ difference test: } & $\mathrm{H}_{2}-\mathrm{H}_{1}$ & $\mathrm{H}_{3}-\mathrm{H}_{2}$ & $\mathrm{H}_{4}-\mathrm{H}_{1}$ \\
\hline CMIN diff & $\chi^{2}$ difference & & 100.7 & 1658.7 & 49.3 \\
\hline diff df & Difference in df & & 16 & 16 & 10 \\
\hline$p$-Value & $p$-Value of CMIN diff & & 0.0000 & 0.0000 & 0.0000 \\
\hline IFI & $>0.95$ & 0.991 & 0.989 & 0.948 & 0.990 \\
\hline TLI & $>0.95$ & 0.986 & 0.984 & 0.935 & 0.985 \\
\hline CFI & $>0.95$ & 0.991 & 0.989 & 0.948 & 0.990 \\
\hline PRATIO & Larger better & 0.636 & 0.717 & 0.798 & 0.687 \\
\hline PNFI & Larger better & 0.629 & 0.707 & 0.754 & 0.678 \\
\hline PCFI & Larger better & 0.631 & 0.709 & 0.757 & 0.680 \\
\hline RMSEA & $<0.05$ & 0.017 & 0.018 & 0.037 & 0.017 \\
\hline LO 90 & $<0.05$ & 0.016 & 0.017 & 0.036 & 0.016 \\
\hline HI 90 & $<0.05$ & 0.019 & 0.020 & 0.038 & 0.019 \\
\hline
\end{tabular}

Table 13

Maximum likelihood estimated parameters ${ }^{\mathrm{a}}$ of model $\mathrm{H}_{4}$ (unstandardised).

\begin{tabular}{|c|c|c|c|c|c|c|c|c|}
\hline \multicolumn{3}{|c|}{ Regression weights } & \multicolumn{2}{|c|}{ Hong Kong } & \multicolumn{2}{|l|}{ Taiwan } & \multicolumn{2}{|l|}{ Thailand } \\
\hline & & & Estimate & $p$ & Estimate & $p$ & Estimate & $p$ \\
\hline \multicolumn{9}{|c|}{ Measurement weights } \\
\hline Finben & $\rightarrow$ & B1 & 1.000 & & 1.000 & & 1.000 & \\
\hline Finben & $\rightarrow$ & B2 & $1.080^{\mathrm{b}}$ & $* * *$ & 1.080 & $* * *$ & 1.080 & $* * *$ \\
\hline Finben & $\rightarrow$ & B3 & 0.972 & $* * *$ & 0.972 & $* * *$ & 0.972 & $* * *$ \\
\hline Infben & $\rightarrow$ & B7 & 1.000 & & 1.000 & & 1.000 & \\
\hline Infben & $\rightarrow$ & B8 & 1.155 & $* * *$ & 1.155 & $* * *$ & 1.155 & $* * *$ \\
\hline Feelings & $\rightarrow$ & $\mathrm{F} 4$ & 1.000 & & 1.000 & & 1.000 & \\
\hline Feelings & $\rightarrow$ & F5 & $1.049^{c}$ & $* * *$ & 1.061 & $* * *$ & 0.915 & $* * *$ \\
\hline Feelings & $\rightarrow$ & F7 & 0.976 & $* * *$ & 0.989 & $* * *$ & 1.099 & $* * *$ \\
\hline Feelings & $\rightarrow$ & F8 & 1.013 & $* * *$ & 0.985 & $* * *$ & 0.961 & $* * *$ \\
\hline Loyalty & $\rightarrow$ & Usefreq & 1.000 & & 1.000 & & 1.000 & \\
\hline Loyalty & $\rightarrow$ & Carrfreq & 1.454 & $* * *$ & 1.727 & $* * *$ & 1.541 & $* * *$ \\
\hline Loyalty & $\rightarrow$ & Recomm & 3.262 & $* * *$ & 2.748 & $* * *$ & 3.586 & $* * *$ \\
\hline \multicolumn{9}{|c|}{ Structural weights } \\
\hline b1: Finben & $\rightarrow$ & Feelings & 0.755 & $* * *$ & 0.566 & $* * *$ & 1.185 & 0.029 \\
\hline b2: Finben & $\rightarrow$ & Loyalty & $0.025^{d}$ & 0.199 & 0.025 & 0.199 & -0.101 & 0.487 \\
\hline b3: Infben & $\rightarrow$ & Feelings & 0.144 & 0.039 & 0.144 & 0.039 & -0.387 & 0.510 \\
\hline b4: Infben & $\rightarrow$ & Loyalty & 0.071 & 0.001 & 0.071 & 0.001 & 0.156 & 0.303 \\
\hline b5: Feelings & $\rightarrow$ & Loyalty & 0.140 & $* * *$ & 0.140 & $* * *$ & 0.177 & $* * *$ \\
\hline \multicolumn{9}{|l|}{ Covariances } \\
\hline Finben & $\leftrightarrow$ & Infben & 0.262 & $* * *$ & 0.320 & $* * *$ & 0.247 & $* * *$ \\
\hline \multicolumn{9}{|l|}{ Correlations $^{\mathrm{e}}$} \\
\hline Finben & $\leftrightarrow$ & Infben & 0.823 & & 0.901 & & 0.957 & \\
\hline \multicolumn{9}{|l|}{ Variances } \\
\hline & & Finben & 0.385 & $* * *$ & 0.415 & $* * *$ & 0.284 & $* * *$ \\
\hline & & Infben & 0.263 & $* * *$ & 0.304 & $* * *$ & 0.235 & $* * *$ \\
\hline & & ee1 & 0.308 & $* * *$ & 0.357 & $* * *$ & 0.260 & $* * *$ \\
\hline & & ee2 & 0.011 & $* * *$ & 0.016 & $* * *$ & 0.012 & $* * *$ \\
\hline
\end{tabular}

${ }^{a}$ For the sake of simplicity, measurement error parameters are not reported, but they are unique for the two countries.

${ }^{\mathrm{b}}$ Parameters in normal text are constrained equal across the three countries.

c Parameters in bold italics are unique across the three countries.

d Parameters in bold (normal text) are constrained equal for Hong Kong and Taiwan, but unique for Thailand.

e Correlations reported from standardised solution. 
Table 14

Total effects, direct effects and indirect effects of model $\mathrm{H}_{4}$ for Hong Kong, Taiwan and Thailand.

\begin{tabular}{|c|c|c|c|c|c|c|c|c|c|c|c|}
\hline & & & \multicolumn{3}{|l|}{ Total effects } & \multicolumn{3}{|l|}{ Direct effects } & \multicolumn{3}{|c|}{ Indirect effects } \\
\hline & & & Hong Kong & Taiwan & Thailand & Hong Kong & Taiwan & Thailand & Hong Kong & Taiwan & Thailand \\
\hline Finben & $\rightarrow$ & B1 & 1.000 & 1.000 & 1.000 & 1.000 & 1.000 & 1.000 & & & \\
\hline Finben & $\rightarrow$ & B2 & $1.080^{\mathrm{a}}$ & 1.080 & 1.080 & 1.080 & 1.080 & 1.080 & & & \\
\hline Finben & $\rightarrow$ & B3 & 0.972 & 0.972 & 0.972 & 0.972 & 0.972 & 0.972 & & & \\
\hline Finben & $\rightarrow$ & Feelings & $0.755^{b}$ & 0.566 & 1.185 & 0.755 & 0.566 & 1.185 & & & \\
\hline Finben & $\rightarrow$ & $\mathrm{F} 4$ & 0.755 & 0.566 & 1.185 & & & & 0.755 & 0.566 & 1.185 \\
\hline Finben & $\rightarrow$ & F5 & 0.792 & 0.601 & 1.085 & & & & 0.792 & 0.601 & 1.085 \\
\hline Finben & $\rightarrow$ & F7 & 0.736 & 0.560 & 1.302 & & & & 0.736 & 0.560 & 1.302 \\
\hline Finben & $\rightarrow$ & F8 & 0.764 & 0.557 & 1.139 & & & & 0.764 & 0.557 & 1.139 \\
\hline Finben & $\rightarrow$ & Loyalty & 0.131 & 0.105 & 0.108 & 0.025 & 0.025 & -0.101 & 0.106 & 0.079 & 0.209 \\
\hline Finben & $\rightarrow$ & Usefreq & 0.131 & 0.105 & 0.108 & & & & 0.131 & 0.105 & 0.108 \\
\hline Finben & $\rightarrow$ & Carrfreq & 0.191 & 0.180 & 0.166 & & & & 0.191 & 0.180 & 0.166 \\
\hline Finben & $\rightarrow$ & Recomm & 0.427 & 0.287 & 0.387 & & & & 0.427 & 0.287 & 0.387 \\
\hline Infben & $\rightarrow$ & B7 & 1.000 & 1.000 & 1.000 & 1.000 & 1.000 & 1.000 & & & \\
\hline Infben & $\rightarrow$ & B8 & $1.155^{c}$ & 1.155 & 1.155 & 1.155 & 1.155 & 1.155 & & & \\
\hline Infben & $\rightarrow$ & Feelings & 0.144 & 0.144 & -0.387 & 0.144 & 0.144 & -0.387 & & & \\
\hline Infben & $\rightarrow$ & F4 & 0.144 & 0.144 & -0.387 & & & & 0.144 & 0.144 & -0.387 \\
\hline Infben & $\rightarrow$ & F5 & 0.151 & 0.153 & -0.354 & & & & 0.151 & 0.153 & -0.354 \\
\hline Infben & $\rightarrow$ & F7 & 0.140 & 0.142 & -0.425 & & & & 0.140 & 0.142 & -0.425 \\
\hline Infben & $\rightarrow$ & F8 & 0.146 & 0.142 & -0.372 & & & & 0.146 & 0.142 & -0.372 \\
\hline Infben & $\rightarrow$ & Loyalty & 0.091 & 0.091 & 0.088 & 0.071 & 0.071 & 0.156 & 0.020 & 0.020 & -0.068 \\
\hline Infben & $\rightarrow$ & Usefreq & 0.091 & 0.091 & 0.088 & & & & 0.091 & 0.091 & 0.088 \\
\hline Infben & $\rightarrow$ & Carrfreq & 0.132 & 0.157 & 0.135 & & & & 0.132 & 0.157 & 0.135 \\
\hline Infben & $\rightarrow$ & Recomm & 0.296 & 0.250 & 0.314 & & & & 0.296 & 0.250 & 0.314 \\
\hline Feelings & $\rightarrow$ & $\mathrm{F} 4$ & 1.000 & 1.000 & 1.000 & 1.000 & 1.000 & 1.000 & & & \\
\hline Feelings & $\rightarrow$ & F5 & 1.049 & 1.061 & 0.915 & 1.049 & 1.061 & 0.915 & & & \\
\hline Feelings & $\rightarrow$ & F7 & 0.976 & 0.989 & 1.099 & 0.976 & 0.989 & 1.099 & & & \\
\hline Feelings & $\rightarrow$ & F8 & 1.013 & 0.985 & 0.961 & 1.013 & 0.985 & 0.961 & & & \\
\hline Feelings & $\rightarrow$ & Loyalty & 0.140 & 0.140 & 0.177 & 0.140 & 0.140 & 0.177 & & & \\
\hline Feelings & $\rightarrow$ & Usefreq & 0.140 & 0.140 & 0.177 & & & & 0.140 & 0.140 & 0.177 \\
\hline Feelings & $\rightarrow$ & Carrfreq & 0.204 & 0.242 & 0.272 & & & & 0.204 & 0.242 & 0.272 \\
\hline Feelings & $\rightarrow$ & Recomm & 0.458 & 0.386 & 0.633 & & & & 0.458 & 0.386 & 0.633 \\
\hline Loyalty & $\rightarrow$ & Usefreq & 1.000 & 1.000 & 1.000 & 1.000 & 1.000 & 1.000 & & & \\
\hline Loyalty & $\rightarrow$ & Carrfreq & 1.454 & 1.727 & 1.541 & 1.454 & 1.727 & 1.541 & & & \\
\hline Loyalty & $\rightarrow$ & Recomm & 3.262 & 2.748 & 3.586 & 3.262 & 2.748 & 3.586 & & & \\
\hline
\end{tabular}

${ }^{\text {a }}$ Estimated effects in normal text are equal due to parameter estimates that constrained equal (in Table 13) across the three countries.

${ }^{b}$ Estimated effects in bold italics are unique due to unique parameter estimates (in Table 13) across the three countries.

c Estimated effects in bold (normal text) are due to parameter estimates (in Table 13) constrained equal for Hong Kong and Taiwan, but unique for Thailand.

Table 15

Maximum likelihood estimated intercepts of Model $\mathrm{H}_{4}$

\begin{tabular}{|c|c|c|c|c|c|c|}
\hline \multirow[b]{2}{*}{ Intercepts } & \multicolumn{2}{|c|}{ Hong Kong } & \multicolumn{2}{|l|}{ Taiwan } & \multicolumn{2}{|l|}{ Thailand } \\
\hline & Estimate & $p$ & Estimate & $p$ & Estimate & $p$ \\
\hline B1 & $0.000^{\mathrm{a}}$ & & 0.000 & & 0.000 & \\
\hline B2 & $-0.482^{b}$ & $* * *$ & -0.315 & $* * *$ & -0.733 & $* * *$ \\
\hline B3 & 0.214 & 0.006 & 0.327 & $* * *$ & 0.035 & 0.672 \\
\hline B8 & -0.630 & $* * *$ & -0.882 & $* * *$ & -0.563 & $* * *$ \\
\hline $\mathrm{F} 4$ & $0.000^{\mathrm{a}}$ & & 0.000 & & 0.000 & \\
\hline F5 & 0.151 & 0.055 & -0.054 & 0.632 & 0.598 & $* * *$ \\
\hline F7 & -0.260 & $* * *$ & -0.269 & $* * *$ & -0.442 & $* * *$ \\
\hline F8 & 0.083 & 0.167 & 0.166 & 0.027 & 0.035 & 0.744 \\
\hline Feelings & -0.319 & 0.005 & 0.761 & $* * *$ & 0.529 & 0.029 \\
\hline Loyalty & 2.891 & $* * *$ & 2.859 & $* * *$ & 2.778 & $* * *$ \\
\hline Usefreq & $0.000^{\mathrm{a}}$ & & 0.000 & & 0.000 & \\
\hline Carrfreq & -1.929 & $* * *$ & -3.363 & $* * *$ & -2.292 & $* * *$ \\
\hline Recomm & -9.939 & $* * *$ & -8.334 & $* * *$ & -10.387 & $* * *$ \\
\hline
\end{tabular}

a In order to identify the model, the intercepts corresponding to the scaling indicator that was constrained equal to one, was set equal to zero.

${ }^{\mathrm{b}}$ Estimated intercepts in bold italics unique across the two countries.

that differ from their Western counterparts, and which significantly impacts on the success of loyalty programmes. Due to the invariance of scales, measurement across different countries and cultures may also not deliver consistently valid results.

Our approach in this paper was to provide an indication of the value of loyalty programmes and to investigate it from both a customer and a loyalty perspective. We addressed the question whether consumer perceptions of the perceived benefits of a loyalty scheme influence both their feelings towards the scheme and loyalty behaviours across five selected Asian countries.

Data collected among members of the Toys'R'Us Star Card loyalty programme across five Asian countries was first subjected 


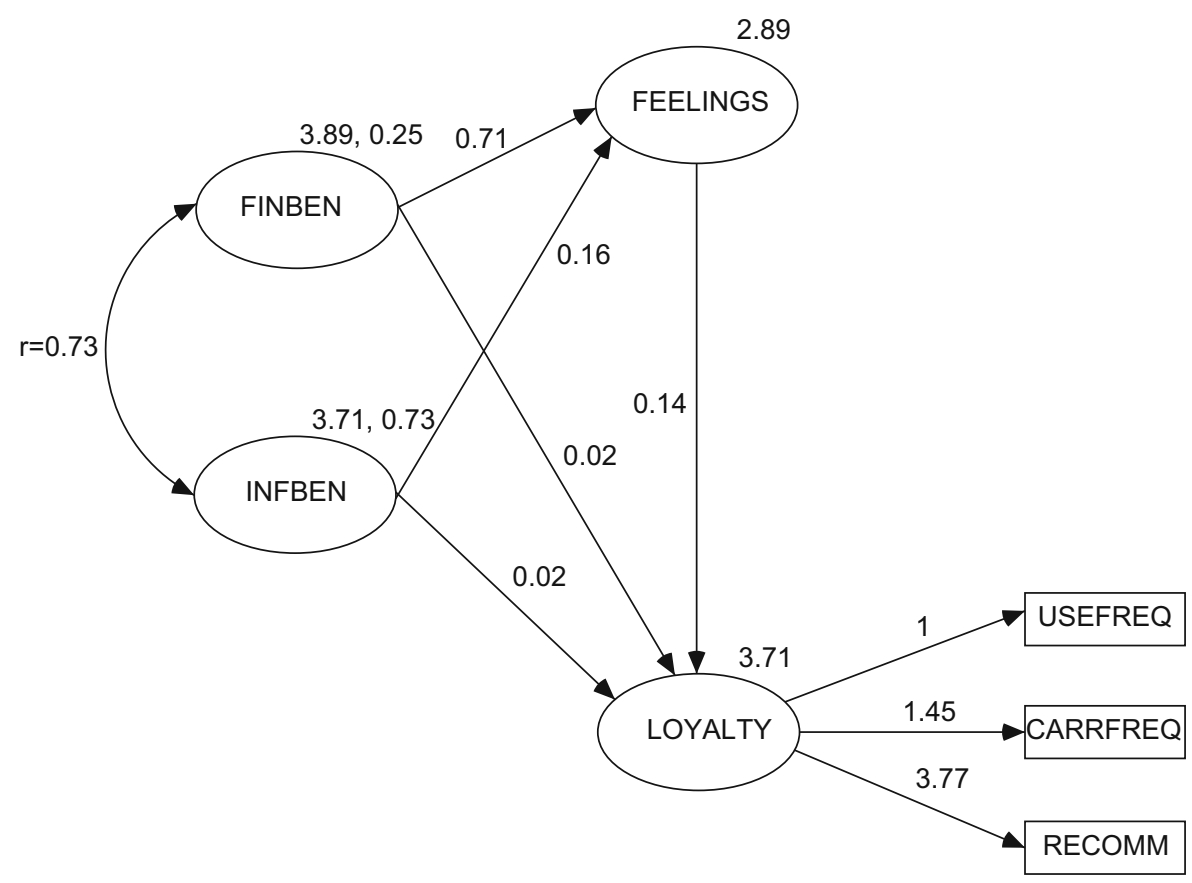

Fig. 3. Model for Singapore.

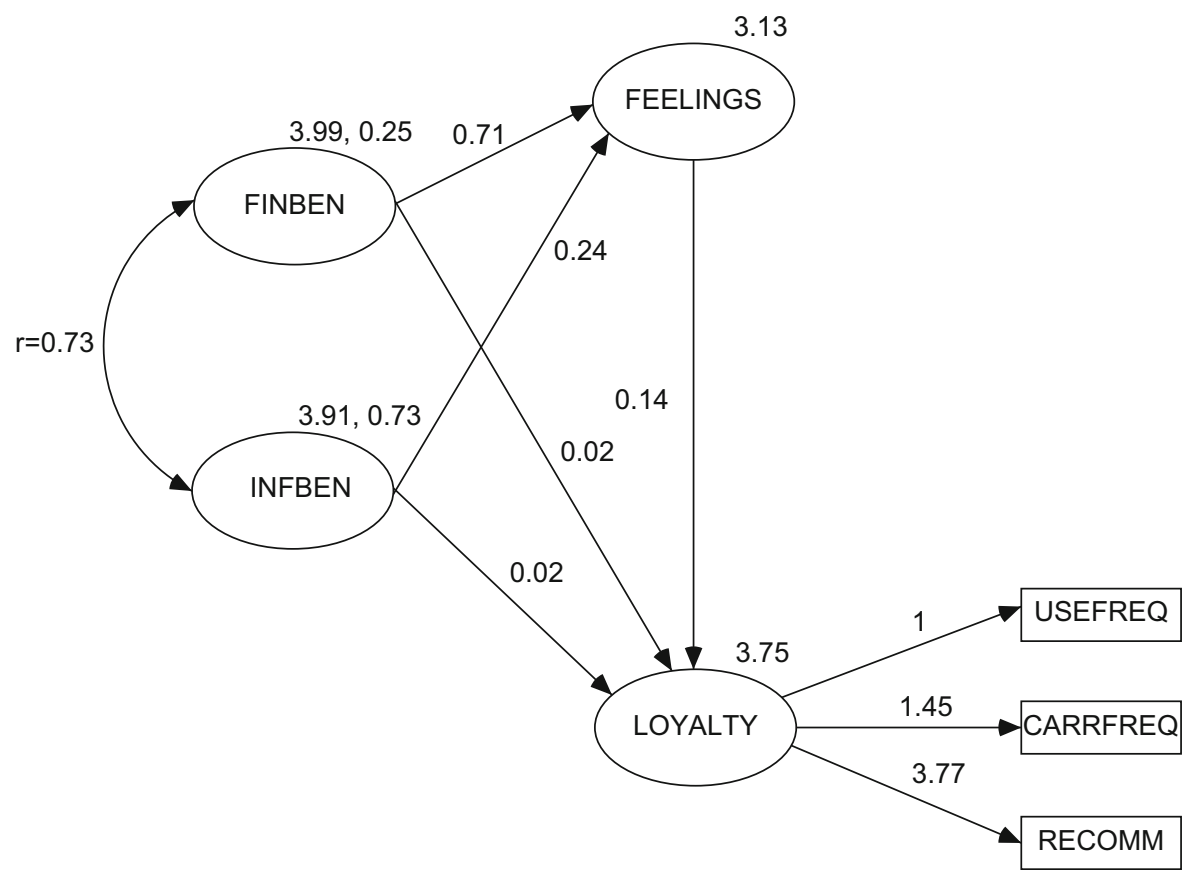

Fig. 4. Model for Malaysia.

to an exploratory principal component factor analysis (EFA) to assess the dimensionality of the data. Second, stepwise regression was used to select the items that were best at predicting the selected predictors of loyalty, and third, structural equation modelling was used to build a model that can be used to explain the simultaneous structural relations between benefits, feelings and loyalty. Finally, invariance testing was applied in order to test whether the model holds across the five countries.

For Hong Kong, Taiwan and Thailand samples, there was a very strong correlation between financial benefits and information benefits. For the Singaporean and Malaysian sample, however, financial benefits and information benefits were weaker correlated, and were certainly perceived as two different aspects with different effects on feelings. When the feeling items were subjected to exploratory principal components factor analysis, a single factor emerged. The structural equation modelling approach in this study was employed to test the relationships among the benefits and feelings, and their relationships with loyalty behaviours, which were indicated by three variables, namely use frequency, carrying the card and recommendations.

In summary, what can be concluded from the different models? The similarities: the same set of items could be used across the five countries to model the relationships between perceived financial and information benefits, feelings about the 


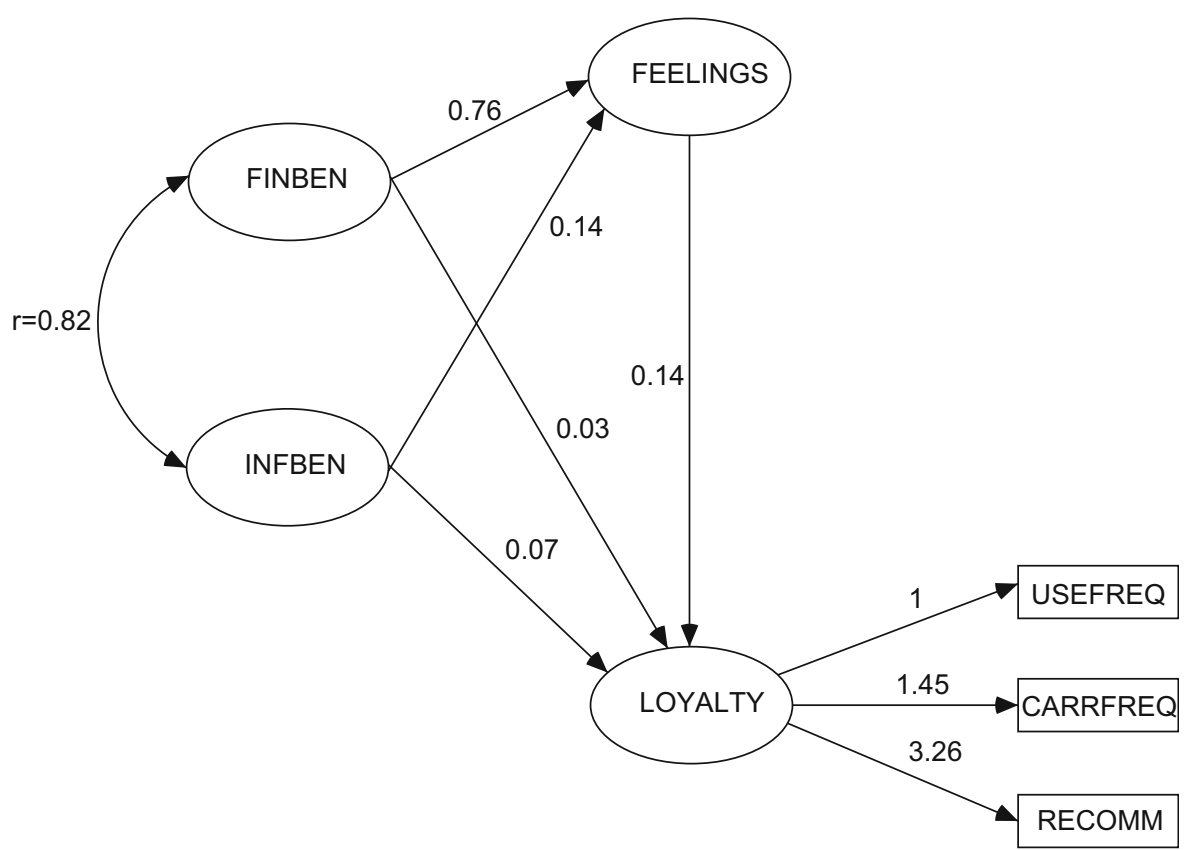

Fig. 5. Model for Hong Kong.

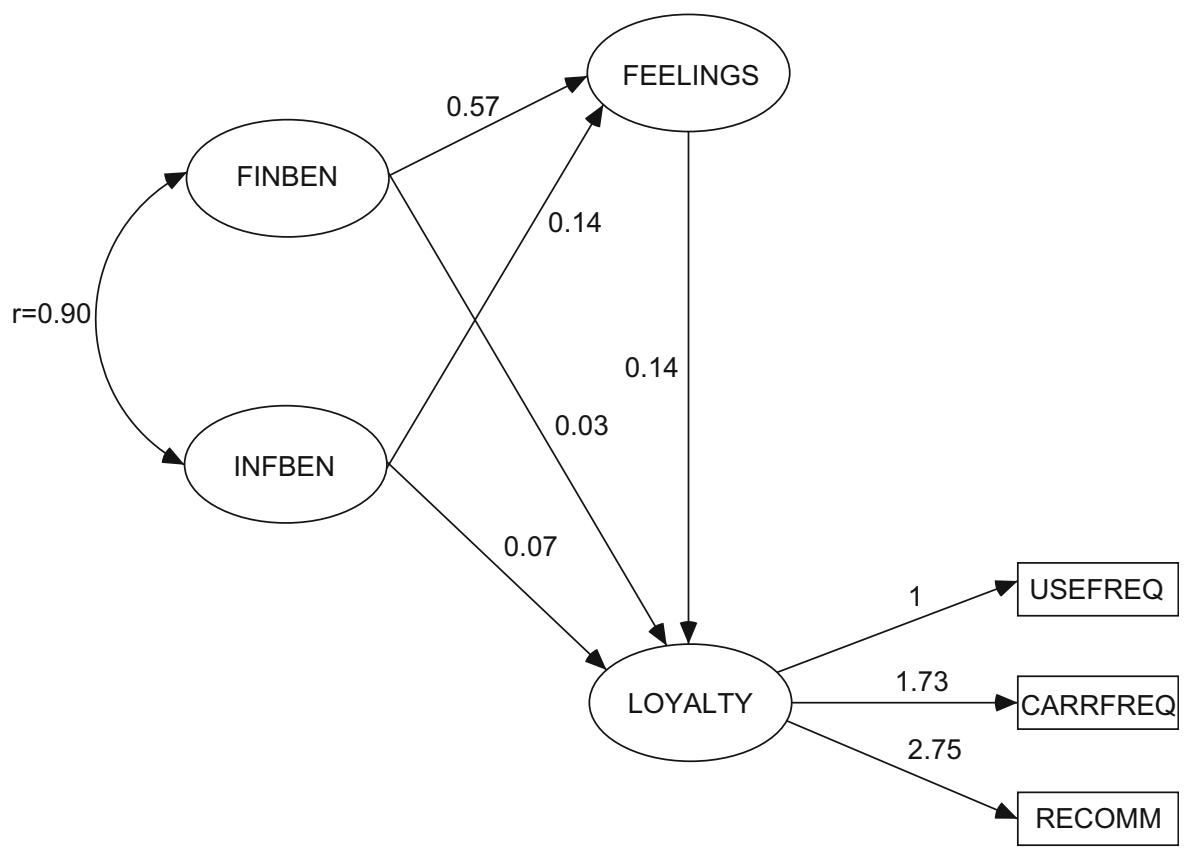

Fig. 6. Model for Taiwan.

card, and loyalty behaviours. Across all five countries, benefits had a stronger effect on feelings than directly on loyalty. Feelings acted as a mediating variable, by translating the perceived benefits to loyalty behaviours. Of the three indicators of loyalty, recommending the loyalty card was a much stronger indicator of loyalty than use frequency or carry frequency.

The differences: how benefits are perceived is probably the biggest difference across the five countries. Malaysian and Singaporean shoppers made a clear distinction between information-related benefits and benefits that they perceived to be of a financial nature. Financial benefits had a stronger effect on feelings that information benefits, however, the only big difference between Malaysia and Singapore was that for Malaysia, the effect of information benefits on feelings was stronger than for
Singapore. On average, the Malaysians seem to perceive both types of benefits somewhat higher than Singaporeans, but the biggest difference in mean levels is how their feelings are influenced about the Star Card. The most interesting is that the resulting effect on their actual loyalty behaviours was not very different, despite the fact that Malaysians had stronger and more positive feelings about the card.

Hong Kong, Taiwan, and most certainly Thailand, seem to see benefits as one cluster of benefits, hence the strong correlation between information and financial benefits. This could possibly be due to them receiving less information than in Singapore or Malaysia, or that the information in the marketing communications and advertising materials could be less valuable and not clearly communicating the benefits. 


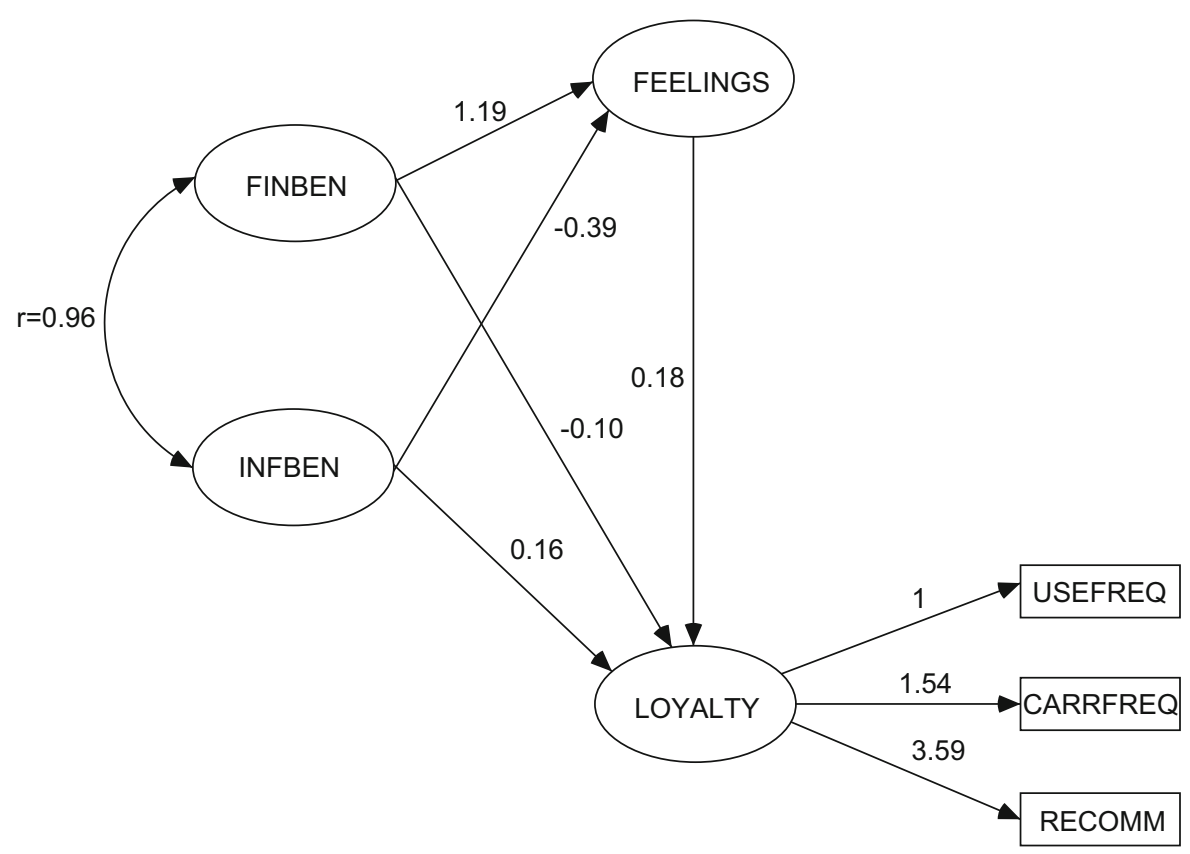

Fig. 7. Model for Thailand.

\section{Managerial implications}

The findings in this research have a number of implications for marketers. The impact of loyalty schemes on actual loyalty measurements such as carrying and usage of the card, and recommending the loyalty programme to others, is not consistent across countries. Shoppers in different countries have different behaviours, loyalty attitudes, and other consumer attitudes and values. Cultural influences may partly explain the variation in these differences which can impact on the successful implementation of loyalty schemes. The possession of loyalty membership in predicting store loyalty and behaviour loyalty varies by country.

There is an opportunity for marketers to create brand communities with the loyalty-card members as they do recommend these cards to others. This indicates that there is some sort of social aspect to card membership.

Marketers need to understand the differences across countries to most effectively design and promote their loyalty schemes. Marketers and their researchers should also consider whether the measurement instrument which is employed to measure the constructs under study in cross-national or cross-cultural research is invariant. Measurement instruments and research results across countries should be validated carefully to differentiate between true differences and systematic biases due to the way people from different cultures respond to scale items. Should they lack evidence supporting a measure's invariance, the interpretation of the results could be erroneous.

More specifically, our research found that retailers should focus on the benefits and feelings items which are the best at predicting the selected predictors of loyalty. This research identified five important benefits items and four feelings items. Loyalty schemes in Malaysia and Singapore should take into consideration that these shoppers make a clear distinction between information-related benefits and financial-related benefits, of which the latter has a stronger effect on feelings. In Hong Kong, Taiwan, and Thailand, shoppers make no such distinction. Furthermore, the path from benefits to loyalty is through feelings. Benefits have a stronger effect on feelings than directly on loyalty, which means that feelings act as a mediating variable by translating the perceived benefits into loyalty behaviours. Finally, of the three indicators of loyalty, recommending the loyalty scheme is a much stronger indicator of loyalty than use frequency or carry frequency, which underscores the importance of measuring recommendation to measure membership loyalty.

\section{Limitations and future research directions}

The study has some limitations. The research is based on only one industry and reflects the opinions of respondents in only five selected countries in Asia and can therefore not be generalised, or compared, across the regions, or with countries in other regions around the world. Future research endeavours may therefore be directed at including different industries and more disparate countries across the Asia Pacific region, as well as regions across the world to support evidence that different countries and different regions may have different behaviours, loyalty attitudes, and other consumer attitudes.

The feelings and benefits measurement scale items employed in the survey instrument have not been validated prior to this study. A scale reliability analysis of the reduced sets of items indicated an acceptable Cronbach's coefficient alpha for the benefits items and a high alpha for the feelings items. Future research may more carefully consider the sets of items included in these scales so that a higher level of reliability may be achieved.

\section{Acknowledgement}

The authors gratefully acknowledge the assistance of Toys LiFung (Asia) Ltd., franchise operators of Toys'R'Us stores in Asia, who allowed the data for analysis and publication.

\section{Appendix}

See Table A1. 
Table A1

\begin{tabular}{|c|c|c|c|c|}
\hline Author(s) & Title & Year & Journal & Overview of study \\
\hline $\begin{array}{l}\text { Demoulin, N.T.M. } \\
\text { and Zidda P. }\end{array}$ & $\begin{array}{l}\text { On the impact of loyalty cards on store } \\
\text { loyalty: does the customers' satisfaction with } \\
\text { the reward scheme matter? }\end{array}$ & 2008 & $\begin{array}{l}\text { Journal of Retailing } \\
\text { and Consumer Services }\end{array}$ & $\begin{array}{l}\text { Loyalty cards are effective only when customers value the } \\
\text { rewards associated with them. When holders are satisfied with } \\
\text { the reward scheme of the loyalty card programme, they are } \\
\text { more loyal and less price sensitive than unsatisfied card holders }\end{array}$ \\
\hline $\begin{array}{l}\text { Leenheer, J. and } \\
\text { Bijomlt, T.H.A. }\end{array}$ & $\begin{array}{l}\text { Which retailers adopt a loyalty program? An } \\
\text { empirical study }\end{array}$ & 2008 & $\begin{array}{l}\text { Journal of Retailing } \\
\text { and Consumer Services }\end{array}$ & $\begin{array}{l}\text { Antecedents of retailers' loyalty programme adoption and their } \\
\text { perceptions regarding loyalty programme effectiveness }\end{array}$ \\
\hline Meyer-Waarden, L. & $\begin{array}{l}\text { The effects of loyalty programs on customer } \\
\text { lifetime duration and share of wallet }\end{array}$ & 2007 & Journal of Retailing & $\begin{array}{l}\text { Loyalty reward schemes have positive effects on customer } \\
\text { lifetimes and share of consumer expenditures, but is effected by } \\
\text { multiple loyalty card memberships }\end{array}$ \\
\hline $\begin{array}{l}\text { Keh, H.T. and Lee, } \\
\text { Y.H. }\end{array}$ & $\begin{array}{l}\text { Do reward programs build loyalty for } \\
\text { services? }\end{array}$ & 2006 & Journal of Retailing & $\begin{array}{l}\text { Examination of two variables in reward programmes: timing } \\
\text { (immediate vs. delayed) and type (direct vs. indirect) of rewards } \\
\text { in two service conditions (satisfied vs. dissatisfied) }\end{array}$ \\
\hline $\begin{array}{l}\text { Bellizzi, J.A. and } \\
\text { Bristol, T. }\end{array}$ & $\begin{array}{l}\text { An assessment of supermarket loyalty cards } \\
\text { in one major US market }\end{array}$ & 2004 & $\begin{array}{l}\text { Journal of Consumer } \\
\text { Marketing }\end{array}$ & $\begin{array}{l}\text { There are a number of factors in addition to loyalty cards that } \\
\text { determine supermarket loyalty }\end{array}$ \\
\hline $\begin{array}{l}\text { Kumar, V. and } \\
\text { Shah, D. }\end{array}$ & $\begin{array}{l}\text { Building and sustaining profitable customer } \\
\text { loyalty for the } 21 \text { st century }\end{array}$ & 2004 & Journal of Retailing & $\begin{array}{l}\text { A conceptual framework for building loyalty and profitability } \\
\text { through loyalty programmes }\end{array}$ \\
\hline $\begin{array}{l}\text { C. Noordhoff, P. } \\
\text { Pauwels, G. } \\
\text { Odekerken- } \\
\text { Schröeder }\end{array}$ & $\begin{array}{l}\text { The effect of Customer Card Programs: a } \\
\text { comparative study in Singapore and the } \\
\text { Netherlands }\end{array}$ & 2004 & $\begin{array}{l}\text { International Journal } \\
\text { of Service Industry } \\
\text { Management }\end{array}$ & $\begin{array}{l}\text { The role of loyalty-card programmes in establishing loyalty } \\
\text { towards a retail store. Found loyalty-card programmes do } \\
\text { impact on attitudinal as well as behavioural store loyalty }\end{array}$ \\
\hline Mauri, C. & $\begin{array}{l}\text { Card loyalty. A new emerging issue in } \\
\text { grocery retailing }\end{array}$ & 2003 & $\begin{array}{l}\text { Journal of Retailing } \\
\text { and Consumer Service }\end{array}$ & $\begin{array}{l}\text { Offers a framework for testing the feasibility that consumers are } \\
\text { card loyal and that they use their cards }\end{array}$ \\
\hline Mãgi, A.W. & $\begin{array}{l}\text { Share of wallet in retailing: the effects of } \\
\text { customer satisfaction, loyalty cards and } \\
\text { shopper characteristics }\end{array}$ & 2003 & Journal of Retailing & $\begin{array}{l}\text { Examines the effects of customer satisfaction and loyalty cards } \\
\text { on customer share spent on the primary grocery store and found } \\
\text { mixed support for the impact of loyalty cards on customer } \\
\text { behaviour }\end{array}$ \\
\hline $\begin{array}{l}\text { Lal, R. and Bell, } \\
\text { D.E. }\end{array}$ & $\begin{array}{l}\text { The impact of frequent shopper programs in } \\
\text { grocery retailing }\end{array}$ & 2003 & $\begin{array}{l}\text { Quantitative } \\
\text { Marketing and } \\
\text { Economics }\end{array}$ & $\begin{array}{l}\text { A model is developed and tested to predict the effects of } \\
\text { frequent shopper programmes }\end{array}$ \\
\hline Byrom, J. & $\begin{array}{l}\text { The role of loyalty card data within local } \\
\text { marketing initiatives }\end{array}$ & 2001 & $\begin{array}{l}\text { International Journal } \\
\text { of Retail \& Distribution } \\
\text { Management }\end{array}$ & The application of loyalty card data to local marketing initiatives \\
\hline $\begin{array}{l}\text { Wright, C. and } \\
\text { Sparks, L. }\end{array}$ & $\begin{array}{l}\text { Loyalty saturation in retailing: exploring the } \\
\text { end of retail loyalty cards? }\end{array}$ & 1999 & $\begin{array}{l}\text { International Journal } \\
\text { of Retail \& Distribution } \\
\text { Management }\end{array}$ & $\begin{array}{l}\text { Demonstrates that since the proliferation of loyalty cards in the } \\
\text { 1990s, consumers are increasing becoming more wary an more } \\
\text { selective of card schemes }\end{array}$ \\
\hline J. Passingham & Grocery retailing and the loyalty card & 1998 & $\begin{array}{l}\text { Journal of the Market } \\
\text { Research Society }\end{array}$ & $\begin{array}{l}\text { Examines the requirement to measure and evaluate loyalty card } \\
\text { performance in a relevant and effective way }\end{array}$ \\
\hline $\begin{array}{l}\text { McGoldrick, P.J. } \\
\text { and Andre, E. }\end{array}$ & $\begin{array}{l}\text { Consumer misbehavior: promiscuity or } \\
\text { loyalty in grocery shopping }\end{array}$ & 1997 & $\begin{array}{l}\text { Journal of Retailing } \\
\text { and Consumer Services }\end{array}$ & $\begin{array}{l}\text { Identified major determinants of loyalty to enhance the } \\
\text { development of integrated, long-term loyalty programmes }\end{array}$ \\
\hline Sopanen, S & Customer loyalty schemes: the bottom line & 1996 & European Retail Digest & $\begin{array}{l}\text { The objectives of the customer loyalty schemes can be divided } \\
\text { into different groups }\end{array}$ \\
\hline $\begin{array}{l}\text { Dick, A.S. and } \\
\text { Basu, K }\end{array}$ & $\begin{array}{l}\text { Customer loyalty: toward an integrated } \\
\text { conceptual framework }\end{array}$ & 1994 & $\begin{array}{l}\text { Journal of the } \\
\text { Academy of Marketing } \\
\text { Science }\end{array}$ & $\begin{array}{l}\text { Contributors to loyalty and their implications for research and } \\
\text { management }\end{array}$ \\
\hline
\end{tabular}

\section{References}

Ackerman, D., Tellis, G., 2001. Can culture affect prices? A cross-cultural study of shopping and retail prices. Journal of Retailing 77, 57-82.

Anisimova, T.A., 2007. The effects of corporate brand attributes on attitudinal and behavioural consumer loyalty. Journal of Consumer Marketing 27 (7), 395-405.

Bagozzi, R., 1994. Structural equation model in marketing research. Basic principles. In: Bagozzi, R.P. (Ed.), Principles of Marketing Research. Blackwell Publishers, Cambridge, MA, pp. 317-385.

Banks, R., 1997. Is Asia different? Defining a strategy to serve multi-national clients in the region. Marketing and Research Today 25 (1), 4-11.

Bellizzi, J.A., Bristol, T., 2004. An assessment of supermarket loyalty cards in one major US market. Journal of Consumer Marketing 21 (2), 144-154.

Berman, B., 2006. Developing an effective customer loyalty program. California Management Review 49 (1), 123-148.

Berry, L.L., 1995. Relationship marketing of services-growing interest, emerging perspectives. Journal of the Academy of Marketing Science 23 (4), 236-245.

Bitner, M.J., 1995. Building service relationships: its all about promises. Journal of the Academy of Marketing Science 23 (3), 246-251.

Bollen, K.A., 1989. Structural Equations with Latent Variables. John Wiley \& Sons, New York.

Briley, D.A., Aaker, J.L., 2006. When does culture matter? Effects of personal knowledge on the correction of culture-based judgments. Journal of Marketing Research 43 (3), 395-408.

Browne, M.W., Cudeck, R., 1993. Alternative ways of assessing model fit. In: Bollen, K.A., Long, J.S. (Eds.), Testing Structural Equation Models. Sage, Newbury Park, CA, pp. 136-162.

Byrne, B.M., 1998. Structural Equation Modeling with LISREL, PRELIS and SIMPLIS: Basic Concepts, Applications and Programming. Lawrence Erlbaum Associates, Publishers, London.
Byrne, B.M., Shavelson, R.J., Muthén, B., 1989. Testing for the equivalence of factor covariance and mean structures: the issue of partial measurement invariance. Psychological Bulletin 105 (3) , 456-466.

Byrom, J., 2001. The role of loyalty card data within local marketing initiatives. International Journal of Retail \& Distribution Management 29 (7), 333-341.

Capizzi, M.T., Ferguson, R., 2005. Loyalty trends for the twenty-first century. Journal of Consumer Marketing 22 (2), 72-80.

Cheung, G.W., Rensvold, R.B., 2000. Assessing extreme and acquiescence response sets in cross-cultural research using structural equation modelling. Journal of Cross-Cultural Research Psychology 31 (2), 187-212.

Collins, N., 2002. It all adds up to a pointless scheme $\langle$ http://www.telegraph.co.uk/ $\rangle$.

Colombo, R.A., Morrison, D.G., 1989. A Brand switching model with implications for marketing strategies. Marketing Science 8 (1), 89-99.

Demoulin, N.T.M., Zidda, P., 2008. On the impact of loyalty cards on store loyalty: does the customers' satisfaction with the reward scheme matter? Journal of Retailing and Consumer Services 15 (5) 386-398.

Dick, A.S., Basu, K., 1994. Customer loyalty: towards an integrated framework Journal of the Academy of Marketing Science 22 (2), 99-113.

East, R., Hammond, K., Harris, P., Lomax, W., 2000. First-store loyalty and retention. Journal of Marketing Management 16 (4), 307-325

Ergin, E.A., Parilti, N., Ozsacmac, B., 2007. Impact of loyalty cards on customers' store loyalty. International Business an Economics Research Journal 6 (2), 77-82.

Ferraro, G.P., 2002. The Cultural Dimensions of International Business, 4th ed Prentice Hall, New Jersey, NJ.

Fox, J., 1980. Effect analysis in structural equation models: extensions and simplified methods of computation. Sociological Methods \& Research 9 (1), $3-28$

Ganesan, V., 2001. Multinational scrambling to enter Asian retailing market. Business Times Malaysia 4 January, 14

Gómez, B.G., Arranz, A.G., Cillán, J.G., 2006. The role of loyalty programs in behaviora and affective loyalty. Journal of Consumer Marketing 23 (7), 387-396. 
Hobbs, R., Rowley, J., 2008. Are pub discount cards loyalty cards? Journal of Consumer Marketing 25 (6) 369-377.

Hofstede, G., 1994. Cultures and organizations: intercultural cooperation and its importance for survival. Harper Collins, London.

Hofstede, G., Bond, M.H., 1998. The confucius connection: from cultural roots to economic growth. Organisational Dynamics, 5-21.

Hu, L.-T., Bentler, P.M., 1999. Cut-off criteria for fit indices in covariance structure analysis: conventional criteria versus new alternatives. Structure Equation Modeling 6 (1), 1-55.

Kim, J., Lim, J.-S., Bhargava, M., 1998. The role of affect in attitude formation: classical conditioning approach. Journal of the Academy of Marketing Science $26,143-152$.

Kivetz, R., Simonson, I., 2003. The idiosyncratic fit heuristic: effort advantage as a determinant of consumer response to loyalty programs. Journal of Marketing Research 40 (4), 454-467.

Kumar, V., Shah, D., 2004. Building and sustaining profitable customer loyalty for the 21st century. Journal of Retailing 80 (4), 317-330.

Lal, R., Bell, D.E., 2003. The impact of frequent shopper programs in grocery retailing. Quantitative Marketing and Economics 1 (2), 179-202.

Lewis, M., 2004. The influence of loyalty programs and short-term promotions on customer retention. Journal of Marketing Research 41, 281-292.

Liebermann, Y., 1999. Membership clubs as a tool for enhancing buyers' patronage. Journal of Business Research 45 (3), 291-297.

Loyalty card fatigue has set in among consumers, 2008. In-Store Marketing, May 15,2008 , p. 5.

Loyalty cards and customer behaviour, 2005. Has the loyalty card had its day in European retailing? (Editor's comments), 2005. Strategic Direction 21 (7) $18-20$.

Mägi, A.W., 2003. Share of wallet in retailing: the effects of customer satisfaction, loyalty cards and shopper characteristic. Journal of Retailing 79, 97-106.

Mauri, C., 2003. Card loyalty. A new emerging issue in grocery retailing. Journal of Retailing and Consumer Services 10 (1), 13-25

Mellens, M., Dekimpe, M.G., Steenkamp, J.E.M., 1996. A review of brand-loyalty measures in marketing. Tijdschrift voor Economie en Management 41 (4) 507-533.

Meyer-Waarden, L., 2007. The effects of loyalty programs on customer lifetime duration and share of wallet. Journal of Retailing 83 (2), 223-236.

Noordhoff, C., Pauwels, P., Odekerken-Schröder, G., 2004. The effect of customer card programs: a comparative study in Singapore and the Nether- lands. International Journal of Service Industry Management 15 (4), 351-364.

Passingham, J., 1998. Grocery retailing and the loyalty card. Journal of the Market Research Society 40 (1), 55-63.

Raykov, T., Marcoulides, G.A., 2000. A First Course in Structural Equation Modeling. Lawrence Erlbaum Associates, Publishers, Mahwah, New Jersey.

Reinartz, W., Kumar, V., 2002. The mismanagement of customer loyalty. Harvard Business Review 80 (7), 86-94.

Retailers play loyalty card, 2008. Bandt.com.au (November, 21): 24-28.

Rosenberg, M.J., Hovland, C.I., 1960. Cognitive, affective, and behavioural components of attitudes. In: Hovland, C.I., Rosenberg, M.J. (Eds.), Attitude Organisation and Change: An Analysis of Consistency Among Attitude Components. Yale University Press, New Haven, CT, pp. 1-14.

Russell-Bennett, R., McColl-Kennedy, J.R., Coote, L.V., 2008. Involvement, satisfaction, and brand loyalty in a small business services setting. Journal of Business Research 60 (12), 1253-1260.

Sharp, B., Sharp, A., 1997. Loyalty programs and their impact on repeat purchase loyalty patterns. International Journal of Research in Marketing 14 (5), 471-486.

Singh, J., Sirdeshmukh, D., 2000. Agency and trust mechanisms in relational exchanges. Journal of the Academy of Marketing Science 28 (1), 150-167.

Sivadas, E., Baker-Prewitt, J.L., 2000. An examination of the relationship between service quality, customer satisfaction, and store loyalty. International Journal of Retail \& Distribution Management 28 (2), 73-82.

Stauss, B., Schmidt, M., Schoeler, A., 2005. Customer frustration in loyalty programs. International Journal of Service Industry Management 16 (3), 229-252.

Steenkamp, J.E.M., Baumgartner, H.B., 1998. Assessing measurement invariance in cross-national consumer research. Journal of Consumer Research 25 (June), 78-90.

Straughan, R.D., Albers-Miller, N.D., 2001. An international investigation of cultural and demographic effects on domestic retail loyalty. International Marketing Review 18 (5), 521-541.

Taylor, G.A., Neslin, S.A., 2005. The current and futures sales impact of a retail frequency reward program. Journal of Retailing 81 (4), 293-305.

Turner, J.J., Wilson, K., 2006. Grocery loyalty: Tesco Clubcard and its impact on loyalty. British Food Journal 108 (11), 958-964.

Wright, C., Sparks, L., 1999. Loyalty saturation in retailing: exploring the end of retail loyalty cards? International Journal of Retail \& Distribution Management 27 (10) 429-439. 